\title{
The complex origin and spatial distribution of non-pure sulfate particles (NSPs) in the stratosphere
}

\author{
Jean-Baptiste Renard ${ }^{1}$, Gwenaël Berthet ${ }^{1}$, Anny-Chantal Levasseur-Regourd ${ }^{2}$, Sergey \\ Beresnev $^{3}$, Alain Miffre ${ }^{4}$, Patrick Rairoux ${ }^{4}$, Damien Vignelles ${ }^{1,5}$, Fabrice Jégou ${ }^{1}$ \\ 1. LPC2E-CNRS, Orléans, France \\ 2. Sorbonne Université, LATMOS-IPSL, Campus Pierre et Marie Curie, Paris, France \\ 3. Ural Federal University, Institute of Natural Sciences and Mathematics, Yekaterinburg, \\ Russia \\ 4. University of Lyon, Université Claude Bernard Lyon 1, CNRS, Institut Lumière Matière, \\ Villeurbanne, France \\ 5. MeteoModem Company, Ury, France
}

\section{Abstract}

While droplets with pure mixtures of water and sulfuric acid are the main component of stratospheric aerosols, field measurements performed for more than 30 years have shown that non-sulfate materials, thereafter referred to by us as NSP (for "Non-pure Sulfate Particles", not considering frozen material) are also present. Such materials, which are released from both the Earth through volcanic eruptions, pollution or biomass burning, and from space through interplanetary dust and micrometeoroids, present a wide variety of composition and shape, with sizes ranging from several $\mathrm{nm}$ to several hundreds of $\mu \mathrm{m}$. No single instrumental technique, from ground, from airplanes, under balloons and onboard satellites using remote-sensing and in-situ instruments. can provide alone a global view of the stratospheric NSPs, which exhibit a strong variability in terms of spatial distribution and composition. To better understand the origin of the NSPs, we have performed new field measurements from mid- 2013 with the Light Optical Aerosol Counter (LOAC) instrument during 135 flights carried out under weather balloons at various latitudes and up to altitudes of $35 \mathrm{~km}$. Coupled with previous measurements obtained with the Tropospheric and Stratospheric Aerosols Counter (STAC) under stratospheric balloons in the $2004-2011$ period, the LOAC measurements show the presence of stratospheric layers presenting enhanced-concentrations associated with NSPs, with a bimodal vertical repartition centered by 17 and $30 \mathrm{~km}$ altitude. Also, large particles are detected, with sizes up to several tens of $\mu \mathrm{m}$, with decreasing concentrations with increasing altitudes. Such observations, which are not correlated with meteor shower events, could be due to dynamical and photophoretic effects lifting and sustaining particles mainly coming from the Earth. When combining all the detections in the stratosphere from different methods of measurements, we may conclude that the concentrations and the vertical distributions of NSPs are highly variable and do not match the estimated concentrations of material in space at Earth orbit. The paper ends by highlighting some open questions on these stratospheric materials and presents some possible new strategies for frequent measurements, to confirm that NSPs are indeed mainly of terrestrial origin, and to better circumvent the NSPs impact on stratospheric chemistry and on the Earth's climate. 


\section{Introduction}

The Earth's stratospheric aerosols mainly contain liquid particles as pure mixture of water and sulfuric acid particles (hereafter referred to as sulfate aerosols or sulfate particles). They largely originate from natural and anthropogenic emissions of oxidized carbonyl sulfide (e.g. Kremser et al., 2016; Günther et al., 2018) or are released from volcanic eruptions injecting the $\mathrm{SO}_{2}$ aerosol precursor directly into the stratosphere (Russell et al., 1996; Deshler et al., 2003; Solomon et al., 2011; Jégou et al., 2013; Bègue et al., 2017), with an altitude of injection controlled by the eruption intensity. Aerosols from volcanic eruptions of moderate amplitude (i.e. about 20 times less $\mathrm{SO}_{2}$ injected than for the Pinatubo major volcanic eruption in 1991) occurring regularly since the year 2000, modulate the sulfate aerosol concentration at the global or hemispherical scale over periods of months (Vernier et al., 2011). Nevertheless, observations of the aerosol content show that particles concentration remains presently low in the northern hemisphere stratosphere, as compared to the post-1991 period impacted by the Pinatubo volcanic eruption. Hence, in what follows, the current stratospheric conditions are typically referred to as "background" aerosol conditions, with sulfate particle concentrations expected to decrease with increasing altitude above $20 \mathrm{~km}$ (Deshler et al., 2006).

Although sulfate particles are the main component of the stratospheric aerosols, at least in the lower and middle stratosphere, remote sensing and in-situ measurements performed for more than 30 years have shown that materials (not considering frozen material) clearly stand out from the sulfate population in terms of composition and optical properties, with abundances depending on the altitude, latitude, and season (Baumgardner et al., 2004; Curtius et al., 2005; Murphy et al., 2007; Renard et al., 2008; Ebert et al., 2016; Schütze et al., 2017). Such materials, that we define here as NSPs, acronym for "Non-pure Sulfate Particles", could be externally-mixed (i.e. pure solid and liquid particles) or internallymixed (i.e. included in or coated by pure sulfate). This definition clusters the various complex properties, mainly in terms of composition, shape and conditions of sublimation, reported in the literature. NSPs can be in the form of semi-volatile particles like some secondary organic aerosols, or volatile liquid particles formed from gaseous precursors, with or without dissolved material. They can contain refractory or non-refractory material in the form of amorphous, compact, aggregated or fractal solid parts like black carbon, thereafter BC, or soot particles (black carbon refer to pure carbon particles, while soot are carbonaceous particles including carbon and other materials). These particles are mostly opticallyabsorbing conversely to pure sulfate particles.

NSPs can have different origins, coming either from the Earth or from space. As detailed below, the strong variability in the corresponding concentration and chemical composition measurements could be due to the various sources, including possible very localized contributions. The expected low concentrations of these particles, the wide variety of their shape and their chemical compositions and the various sensitivity of the measurement techniques have not, up to now, made it possible to reach a comprehensive vision of non-sulfate materials in the stratosphere in terms of origins, content, physical properties, composition and seasonal/inter-annual variability, which would be necessary to address different questions such as radiative effects.

The aim of this paper is to contribute to a better understanding of NSPs origins and variability in the stratosphere. For that purpose, we have developed a new strategy of measurements, using the Light Optical Aerosols Counter (LOAC), which has performed 135 


\begin{abstract}
flights under weather balloons over the mid-2013 - mid-2019 period. We first present the methodologies already used for the NSPs detection; then, we present the LOAC instrument and the results obtained for concentrations, size distribution, temporal and spatial variabilities; finally we discuss the possible origins of such variabilities, and the contribution of LOAC to better estimate the source of the NSPs.
\end{abstract}

\title{
2. Present methodologies for NSPs detection in the stratosphere
}

\subsection{Context}

NSPs have been detected using different remote-sensing and in-situ instruments, from the ground, onboard airplanes, under balloons and onboard satellites. None of these instruments can solely characterize these particles at all possible scales, from the detection of specific events to the observation of the spatial and temporal variability of their concentrations, size distributions and chemical composition. Then, all these measurements must be combined to tentatively propose a comprehensive view of NSPs in the stratosphere.

\subsection{Ground-based measurements}

Ground-based observations provide sparse or time-series measurements from a given place, meaning that fortuitous events of stratospheric aerosol enhancements with or without NSPs can be detected.

Remote-sensing photometric measurements at twilight can provide vertical profiles of twilight intensity that reflect the aerosol abundances. However, such measurements have been seldom conducted, mainly during meteor shower episodes, showing strong and transient aerosols enhancements in the middle and upper stratosphere (Padma Kumari et al., 2005, 2008).

Other transient episodes have been reported from lidar measurements, in relation with the disintegration of a meteorite (Klekociuk et al. 2005), or the debris of rockets or satellites (Gerding et al., 2003), or wildfire plume events (Siebert et al., 2000; Khaykin et al., 2018; Haarig et al., 2018). Most of these measurements are performed in the framework of the Network for the Detection of Atmospheric Composition Change (NDACC) or European Aerosol Research Lidar Network (5EARLINET). There is however no direct determination of the precise size distribution and concentration of the particles, although indications on the altitude dependency of their nature (liquid, solid, mixed) and their mean size values can be derived from the depolarization they induce on the backscattered laser light (Stein et al., 1994). Such analyses are conducted from an optical point of view by partitioning the stratospheric aerosol into icy particles and spherical particles containing sulfate component, which backscatter light is well-known, and non-sulfate optical component that mainly refers to light-absorbing material including BC and soot. In particular, such a partitioning was already performed by Miffre et al. (2015) in the troposphere when coupling incandescence and lidar field measurements. 


\subsection{Airplane measurements}

Airplanes can perform long horizontal excursions but shorter vertical profiles excursions in the lower stratosphere up to about $22 \mathrm{~km}$ altitude, by carrying instruments for in-situ measurements. The measurements are conducted during dedicated field campaigns, thus providing accurate but sparse measurements that might not be representative of the whole lower stratosphere. The main difficulty could be the collection of very large particles greater than several tens of $\mu \mathrm{m}$, although specific collecting methods have been developed to limit the possible breaking of the particles due to relative speeds of up to $200 \mathrm{~m} / \mathrm{s}$ (e. g. Scott and Chittenden, 2002).

Historically, the first campaigns were conducted to collect interplanetary dust, with subsequent laboratory analysis by electronic microscopy (TEM/SEM) and energy-dispersive X-ray microanalysis (Brownlee, 1985; Warren and Zolensky, 1996). NASA has been collecting dust in the stratosphere since the beginning of 1981, with U-2, ER-2 and WB-57 airplanes. These flights have mostly ranged over most of the USA (as far as north as Alaska) and Central America. The main challenging tasks are to distinguish between the refractory material coming either from space or from the Earth itself and to determine the natural or anthropogenic origin of these particles through morphology and composition analyzes (Pueschel et al., 1992; Blake and Kato, 1995; Pueschel et al., 1997; Strawa et al., 1999; Ebert et al., 2016; Schütze et al., 2017).

In-situ optical counting instruments onboard airplanes provide the size distribution of the particles in the lower stratosphere, for particles greater than about $0.2 \mu \mathrm{m}$. Conventional counters are highly sensitive to the complex refractive index of the particles; $\mathrm{BC}$ particles can typically be up to 10 times darker than liquid sulfuric-acid aerosols of the same size. To accurately retrieve the size distribution, the nature of the detected aerosols must be known when processing the data, otherwise the contribution of the optically-absorbing particles could be strongly underestimated. A more sophisticated methodology consists in using a first channel specifically for the determination of the total aerosol concentration and a second one heated to $250^{\circ} \mathrm{C}$ detecting the presence of non-volatile materials. The fraction of stratospheric particles not composed entirely of volatile (i.e. water and sulfuric acid) material is then estimated by calculating the difference between both channels (Curtius et al., 2005).

The in-situ scattering and incandescence techniques, where the aerosols are also heated, is used to determine the size distribution of the submicron particles down to $0.2 \mu \mathrm{m}$, the proportion of light-absorbing refractory NSPs, the determination of bulk composition (such a BC) and information about the possible presence of coating (Baumgardner et al., 2004; Schwarz et al., 2006; Weigel et al., 2014).

Finally, the in-situ mass spectrometry provides the composition of the particles and the vertical profile of the partitioning between various families of NSPs containing or not carbonaceous material and metals (Murphy et al., 1998; Jost et al., 2004; Murphy et al., 2007; Murphy et al., 2014). However, from this technique it is difficult to conclude whether the metallic elements are dissolved or are in the form of refractory inclusions in the sulfate particles. 


\subsection{Balloon-borne measurements}

Stratospheric (zero pressure) balloons can reach $40 \mathrm{~km}$ altitude and stay up to a few tens of hours in flight. They are well-adapted to study the middle stratosphere above altitudes reached by airplanes. Measurements can be conducted during ascent, at float and during a slow descent. However, technical and operational constraints strongly restrain the number of flights and the geographic zones for launches.

Remote sensing measurements, using natural light sources (Sun, Moon, stars) can provide the vertical profile of aerosols extinction with a resolution of a few hundreds of meters, generally in the UV-visible domain (Renard et al., 2002). For liquid aerosols, the size distribution can be retrieved using Mie scattering calculations. Such an observational method needs to assume that the stratosphere is composed of horizontally homogeneous layers along lines of sight of tens to hundreds of $\mathrm{km}$ long, although significant local concentration variations can bias the retrieval (Berthet et al. 2007). Nevertheless, nonmonotonous UV-visible extinctions could be an indicator of the possible presence of optically absorbing material in the stratosphere together with the sulfate aerosol population (Berthet et al., 2002; Renard et al., 2002). Also, the measurements of the local radiance scattering function for the aerosols (Mishchenko, et al., 2004) can be used to distinguish between sulfate and other types of particles (Renard et al. 2008). However, such studies have not addressed the possibility for the aerosols to be internally or externally-mixed.

The optical aerosol counters are easier to use from balloons than from airplanes, since the relative speed between the instrument and the ambient air is low, around $5 \mathrm{~m} / \mathrm{s}$ during ascent or slow descent and close to zero at float. They can typically detect particles with sizes from about $0.2 \mu \mathrm{m}$ to a few $\mu \mathrm{m}$ (Deshler et al., 2006; Renard et al., 2005), and provide the vertical profiles of the aerosols for several size classes. An improved optical particle counter has been used to detect the fraction of aerosols that are charged, probably by the galactic cosmic rays (Renard et al., 2013). Such charged particles could have some implication in the high-energy phenomena in the middle and upper atmosphere (Füllekrug et al., 2013).

Finally, the negligible speed between the balloon and the ambient air at float altitude is optimal to collect the particles without breaking them. As for airplane collection, the particles are analyzed in the laboratory after a soft landing of the gondola (Testa et al., 1990; Ciucci et al., 2008; Della Corte et al., 2013).

\subsection{Satellite measurements}

Satellite instruments can provide a global coverage of the aerosol content in the stratosphere (Bingen et al., 2004; Vanhellemont et al., 2010; Vernier et al., 2011; Salazar et al., 2013; Thomason et al., 2018). They can be used to derive trends over several years or to study locally strong sources of aerosols. For such remote sensing measurements, inversion methods are necessary to retrieve the vertical profiles, using assumptions on the complex refractive index of the particles and/or on the shape of the size distribution (e.g. Bourassa et al., 2012). Nevertheless, they cannot access to the local variability of the aerosol content, which can be potentially diluted along the line of sight and/or could be removed when applying smoothing or filtering procedures. 
The UV-visible extinction measurements obtained from occultation or from limb profiling rely on the hypothesis of homogeneous layers in the stratosphere. The vertical resolution is between one and a few $\mathrm{km}$. Nevertheless, it is possible to follow intense events of injection of refractory material in the stratosphere from fires (carbonaceous particles), volcanoes (ash) and meteoroid disintegration (Fromm and Servranckx, 2003; Fromm et al. 2006; Niemeier et al., 2009; Gorkavyi et al., 2013; Rieger et al., 2014). Also, extinction measurements can be used to search for the presence of NSPs with respect to the pure sulfate population in the middle stratosphere (Neely et al., 2011).

The space-borne lidar measurements, like the CALIOP instrument onboard the Calipso satellite, are mainly dedicated to cloud studies, tropospheric aerosols and the boundary layer (e. g. Bourgeois et al., 2018), since the scattered signal is often too low for the detection of stratospheric aerosols. Also, reference altitudes used to derive the Rayleigh signature in the lidar retrieval and assumed to be aerosol-free are often too low to detect stratospheric aerosols in general above $30 \mathrm{~km}$ altitude (Vernier et al., 2009). Nevertheless, analyses can be conducted during specific events such as a volcanic eruption and injections of carbonaceous particles and/or the gaseous precursors by the Asian monsoon or pyroconvection (Vernier et al., 2016; Govardhan et al., 2017; Vernier et al., 2018; Khaykin et al., 2018).

Finally, attempts to collect dust from space entering the Earth's atmosphere were made from Gemini 10, Skylab, Salyut 7 and MIR space stations, and from the retrieval of space exposed surfaces of satellites. The Long Duration Exposure Facility (LDEF) was exposed for almost 6 years at altitudes ranging from $580 \mathrm{~km}$ to $332 \mathrm{~km}$, and provided evidence for micrometeoroids (Mandeville et al., 1991; Love and Brownlee, 1993; Kalashnikova et al., 2000) that do enter the Earth's atmosphere.

\section{Regular flights with balloon-borne aerosols counters}

\subsection{Instruments for stratospheric studies}

The previous measurements have shown that the stratospheric content of NSPS exhibits a strong horizontal, vertical and temporal variability, since the sources of NSPs can be diverse. Regular and frequent in situ measurements are of high relevance to derive the stratospheric aerosols content and to follow its evolution, because the use of a priori hypothesis on the shape, the composition and the size distribution of the particles commonly used in data retrievals from remote sensing instruments (e.g. Bourassa et al., 2012) is at least minimized or at best pointless. Such measurements strategy with aerosols counters under balloons started about 50 years ago.

The University of Wyoming aerosols counters (Deshler et al., 2003; Deshler et al., 2006) and the Stratospheric and Tropospheric Aerosols Counter (STAC) (Renard et al., 2008; Renard et al., 2010) have provided locally the size distribution and the concentrations of aerosols up to $40 \mathrm{~km}$ in altitude when launched under (large) stratospheric balloons. In particular, during its 21 flights in the 2004 - 2011 period, STAC has often detected strong aerosol concentration enhancements over a vertical extent from few hundreds of meters to few km.

Such instruments were calibrated for the detection of liquid particles typically in the $0.2-5 \mu \mathrm{m}$ size range. Since their measurement technique is sensitive to the complex 
refractive index of the particles, these instruments cannot be used to distinguish between transparent liquid particles and optically absorbing NSPs, the size of the latest being possibly underestimated. The weight of the instrument is of several $\mathrm{kg}$, preventing them to be used under small balloons as weather balloons.

Given that the aerosol variability does not necessarily vary homogeneously throughout the stratosphere especially under the influence of sporadic events (volcanic eruptions, fires, meteoroid disintegrations), regular and frequent in-situ measurements must be conducted from several locations in the world. Accounting for operational constraints and cost issues, it seems that the most valuable method is to launch light and inexpensive instruments under weather balloons, sending the data by a telemetry system, with the risk of losing the instrument after the flight. Such types of balloons can reach an altitude of 35 $\mathrm{km}$, but the burst of the balloon cannot be controlled. The payload weight must be below a few kg to account for the international aeronautic rules. The cost for the balloons and the gas are no more than a few hundreds of euros. Two or three people are necessary to launch the balloon from almost everywhere in the world. The wind speed at ground could be up to $15 \mathrm{~m} / \mathrm{s}$. Then, frequent measurements, typically tens of flights per year, can be conducted regularly and during specific events almost from everywhere.

Light instruments are not currently available for collecting systems or for massspectrometry. On the opposite, two light optical aerosols counter with a weight of about 1 $\mathrm{kg}$ are now available on the market. The first one is the Printed Optical Particle Spectrometer (POPS), designed for the detection of liquid particles in the $\sim 0.15-1 \mu \mathrm{m}$ size range (Gao et al., 2016). It can provide very accurate size distributions and concentrations of sub-micronic sulfate stratospheric aerosols with a vertical resolution of $100 \mathrm{~m}$ or better, but is not designed to detect the largest particles previously detected in the stratosphere (e.g. Jessberger et al., 2001; Ciucci et al., 2008) and cannot identify the optically absorbing particles. The second one is the Light Optical Aerosols Counter (LOAC). LOAC is a novel instrumental concept (Renard et al., 2016a), providing the size distributions, the concentrations, and an estimate of the typology, for particles in the $0.2-50 \mu \mathrm{m}$ size range. LOAC uses a statistical approach to retrieve the concentration of particles smaller than $1 \mu \mathrm{m}$ (Renard et al., 2016a). When the concentration of submicronic particles is low, typically below 10 particles $\mathrm{cm}^{-3}$ for sizes greater than $0.2 \mu \mathrm{m}$, the integration time must be increased up to $10 \mathrm{~min}$; then the vertical resolution is between $1 \mathrm{~km}$ and $3 \mathrm{~km}$ for a balloon ascent speed of about $5 \mathrm{~m} / \mathrm{s}$. Since LOAC is not sensitive to the complex refractive index of the particles, it can detect all particle types. LOAC is well appropriated for the detection of the NSPs, as previously shown for dust particles in the troposphere (Renard et al., 2018), while the POPS is better designed for the detection of the submicronic sulfate aerosols; then these two instruments could be considered as complementary.

\subsection{The LOAC instrument}

The particles are injected through an optical chamber by a pumping system, cross a laser beam and the light scattered by the particles is recorded by two detectors. Conventional aerosols counters typically performed measurements at large scattering angles (greater than $30^{\circ}$ and often around $90^{\circ}$ ). Since the scattered light is sensitive to the size of the particles but also to their complex refractive index and their shape including porosity effects, conventional optical counter measurements must be corrected for the nature of the 
particles. On the opposite, LOAC performs measurement at small scattering angles, in the $11^{\circ}-16^{\circ}$ range, where the scattered light is mainly coming from diffraction that does not depend on the complex refractive index nor on the porosity of the irregular-shaped particles (Lurton et al. 2014). As a result, a direct correspondence between the intensity of the scattered light and the optical diameter of the particles becomes feasible. LOAC provides particles number concentrations for 19 sizes in the $0.2-50 \mu \mathrm{m}$ size range, with an uncertainty of $\pm 20 \%$ for concentrations higher than 10 particles $\mathrm{cm}^{-3}$; the uncertainty increases to about $\pm 30 \%$ for submicronic particle concentrations higher than 1 particle $\mathrm{cm}^{-3}$, and to about $\pm 60 \%$ for concentrations smaller than $10^{-2}$ particle $\mathrm{cm}^{-3}$. The size of the particles provided by LOAC is an optical diameter, which could differ from aerodynamical, electric mobility and gyration diameters used by other counting techniques in case of irregular particles. Also, the refractory particles could be hydrated, thus having a size greater than dry particles. The ability of LOAC to accurately detect micron-sized particles and larger particles has been validated during numerous intercomparaison sessions with different instruments (Renard et al., 2016a; Renard et al., 2018).

LOAC has a second detector at a scattering angle in the $50^{\circ}-70^{\circ}$ range, where the scattered light is very sensitive to the complex refractive index and to the porosity of the particles. By statistically combining these measurements with those at $11-16^{\circ}$, we obtain a parameter called "speciation index", which is representative of the properties of the particles to absorb light (Renard et al., 2016a). Higher is the speciation index, darker are the particles. Speciation index reference measurements were conducted in laboratory with pure reference samples to establish a data base. By comparing the ambient air measurements to the database, we can tentatively identify the basic nature of the particles, or typology. As confirmed during tests in laboratory and in ambient air, LOAC can indicate if the detected aerosols are icy, are in a non-optically absorbing liquid phase as the typical stratospheric pure sulfate population, are semi-transparent NSPs as some dry minerals or highly hydrated solid aerosols, or are optically-absorbing NSPs as carbonaceous particles. For the last case, it is not possible however to know if the particles are externally or internally-mixed with sulfate, or can be considered as a secondary organic aerosol. This approach is just a first step to validate the ability of optical measurements to provide an estimate of the nature of the stratospheric aerosols.

The raw LOAC concentrations are corrected of the sampling efficiency when the measurements are conducted under weather balloon (Renard et al., 2016a), the sampling being dominated by sub-isokinetic conditions and the divergence of the flow field at the inlet entrance.

\subsection{Vertical profile of aerosol concentrations obtained with LOAC}

The LOAC gondola includes batteries, telemetry to send the data in real time, and temperature and humidity sensors, using the MeteoModem Company system (Renard et al., 2016b). Since May 2013 to mid-2019, 135 flights reaching the stratosphere have been successfully conducted from France, from Spain and from lle de la Réunion (Indian Ocean). Regular flights, from one to four per month, have been operated since February 2014 from France mainly by Centre National d'Etudes Spatiales (CNES), the French Space Agency, from its balloons launching base at Aire sur l'Adour $\left(43.70^{\circ} \mathrm{N}, 0.25^{\circ} \mathrm{W}\right)$; in this case the balloons are called "Light Dilatable Balloons" since they carry a scientific instrument, to distinguish 
them for conventional weather balloons. Figure 1 presents a LOAC launch from Aire sur l'Adour on 6 February 2014.

Figure 2 presents an example of the vertical evolution of the particle number concentrations for a LOAC flight in 17 August 2017, again from Aire sur l'Adour. Concentrations decrease with altitude, as expected for sulfate aerosols. The retrieved typologies in the stratosphere indicate that the submicron aerosols are indeed transparent liquid droplets based on the comparison with reference curves obtained in the laboratory with this type of particles (Figure 3). Note that in this example the number of detected particles for size classes above $3 \mu \mathrm{m}$ is too low for the typology determination.

Few particles greater than $5 \mu \mathrm{m}$ are detected above the tropopause, and one particle larger than $40 \mu \mathrm{m}$ is present at $25 \mathrm{~km}$ altitude. Since the flight was conducted while the permanent Perseids meteor shower took place, one could suggest that LOAC has detected some dust particles coming from space.

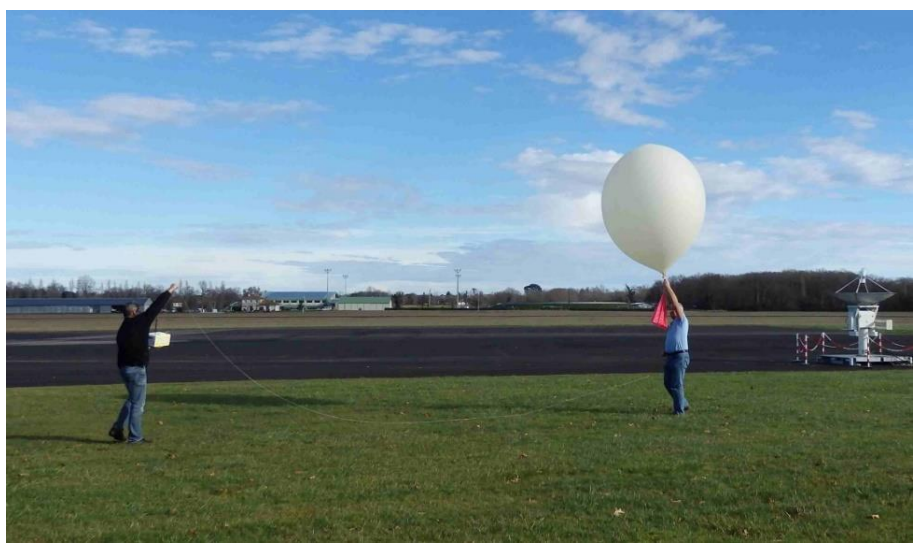

Figure 1: LOAC launch from Aire sur l'Adour (France; $43.70^{\circ} \mathrm{N}, 0.25^{\circ} \mathrm{W}$ ) on 6 February 2014

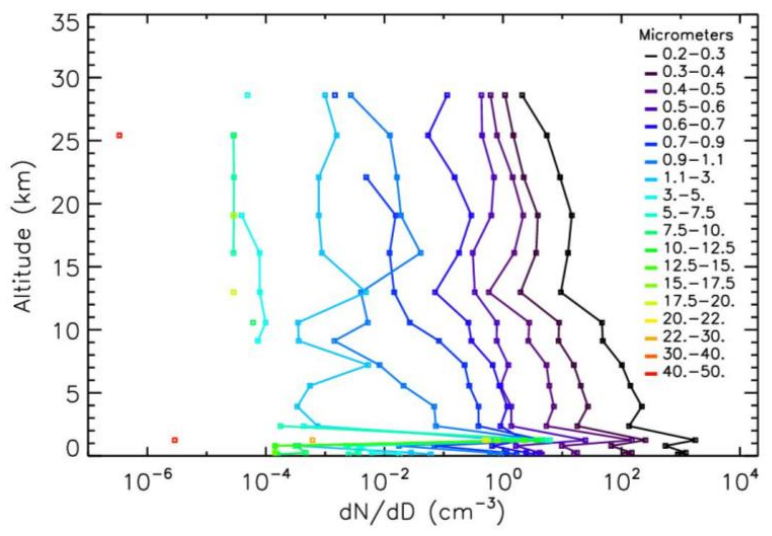

Figure 2: Vertical profile for the LOAC 17 August 2017 flight from Aire sur l'Adour (France; $43.70^{\circ} \mathrm{N}, 0.25^{\circ} \mathrm{W}$ ) during the Perseids meteor shower period. Errors bars (see text) are omitted for clarity reasons 


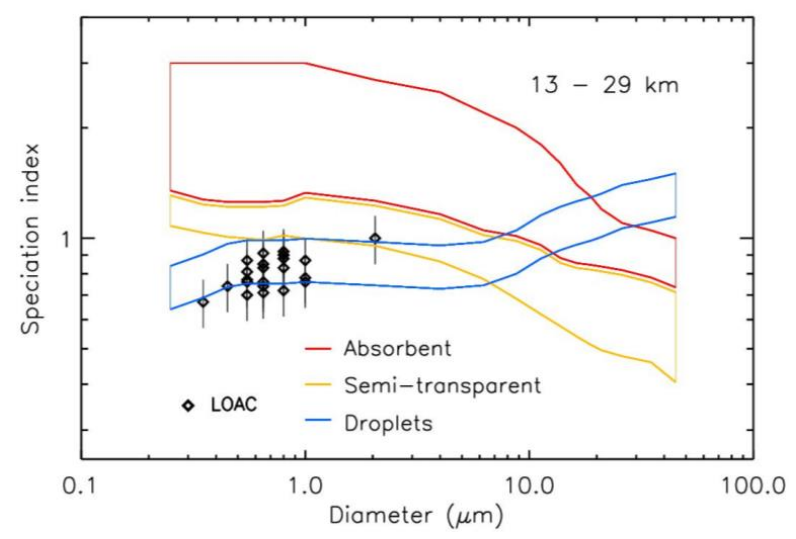

Figure 3: Indications of typology from the LOAC speciation index in the stratosphere for the 17 August 2017 flight

LOAC has detected some strong vertical variability of aerosol concentrations during flights in background conditions (without recent volcanic eruptions). We consider here that a strong concentration enhancement is detected whenever the concentrations are at least 5 times higher than the background concentrations measured during the same flight for at least 5 consecutive size classes (this criterion is to ensure that the enhancements are real and are not due to noise measurement fluctuations). We exclude the measurements conducted at the edge of the polar vortex where the local dynamical variability can affect the aerosols content (Renard et al., 2008).

Figure 4 presents an example of a strong concentration enhancement in the lower stratosphere at an altitude of $18 \mathrm{~km}$, as observed during a flight conducted from Aire sur I'Adour on 11 August 2016, during the Perseids period. Several particles bigger than $5 \mu \mathrm{m}$ have been also detected at this altitude, which could result from the fragmentation of a larger fluffy particle or could be an accumulation layer of carbonaceous particles (note that the large particles between 8 and $12 \mathrm{~km}$ altitude correspond to a cirrus cloud). The typology (Figure 5) indicates that particles up to $2 \mu \mathrm{m}$ are indeed in liquid phase, in this case certainly sulfates, while biggest ones are classified as strongly optically-absorbing NSPs.

Figure 6 presents another example of concentration enhancement observed in the middle stratosphere at an altitude of $28 \mathrm{~km}$ and only for submicronic particles, during a flight on 23 November 2017 from Aire sur l'Adour. This time, the typology (Figure 7) indicates mainly optically-absorbing particles for the smaller size classes. 
https://doi.org/10.5194/acp-2019-904

Preprint. Discussion started: 3 December 2019

(c) Author(s) 2019. CC BY 4.0 License.
Atmospheric

Chemistry

and Physics

Discussions
424

425

426

427

428

429

430

431

432

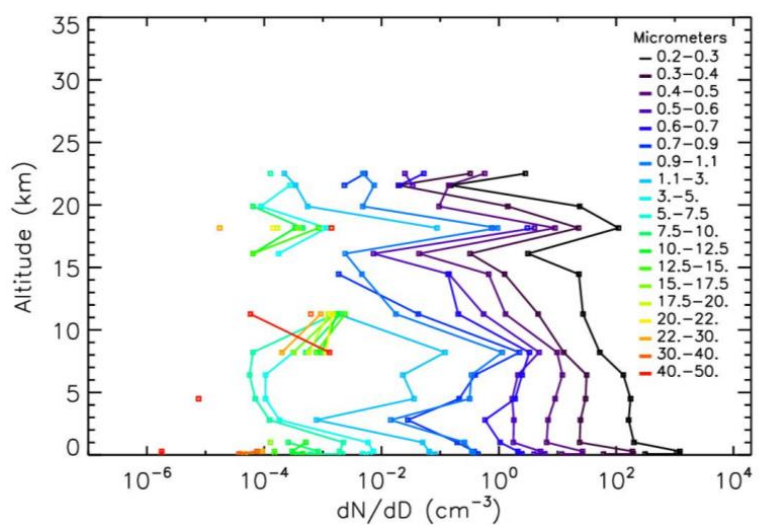

Figure 4: Vertical profile for the LOAC 11 August 2016 flight from Aire sur l'Adour (France; $43.70^{\circ} \mathrm{N}, 0.25^{\circ} \mathrm{W}$ ) during the Perseids meteor shower period. Errors bars (see text) are omitted for clarity reasons

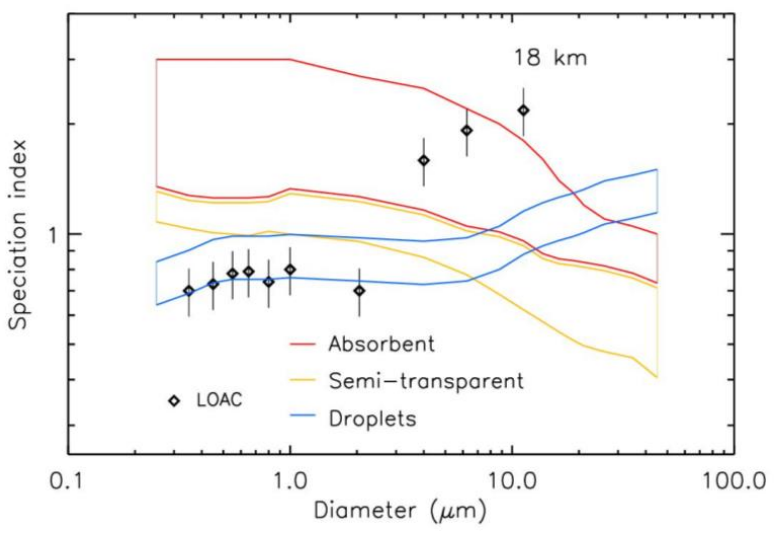

Figure 5: Indications of typologies from the LOAC speciation index in the stratosphere for the 11 August 2016 flight

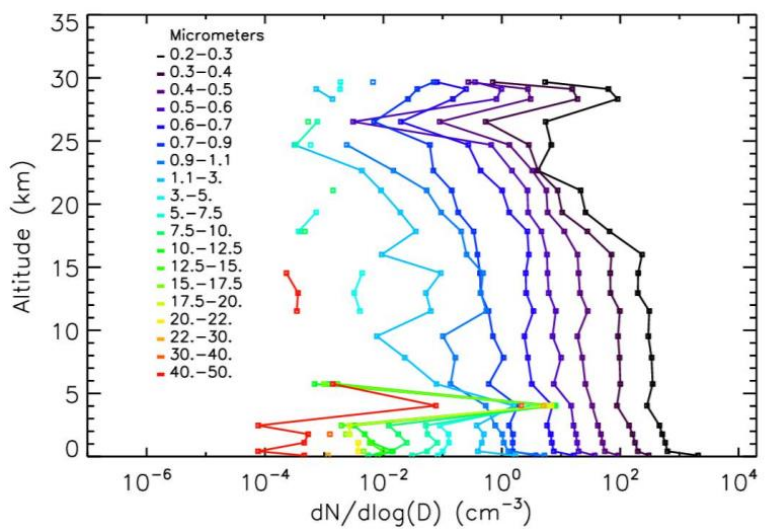

Figure 6: Vertical profile for the LOAC 23 November 2017 flight from Aire sur l'Adour (France; $43.70^{\circ} \mathrm{N}, 0.25^{\circ} \mathrm{W}$ ). Errors bars (see text) are omitted for clarity reasons 


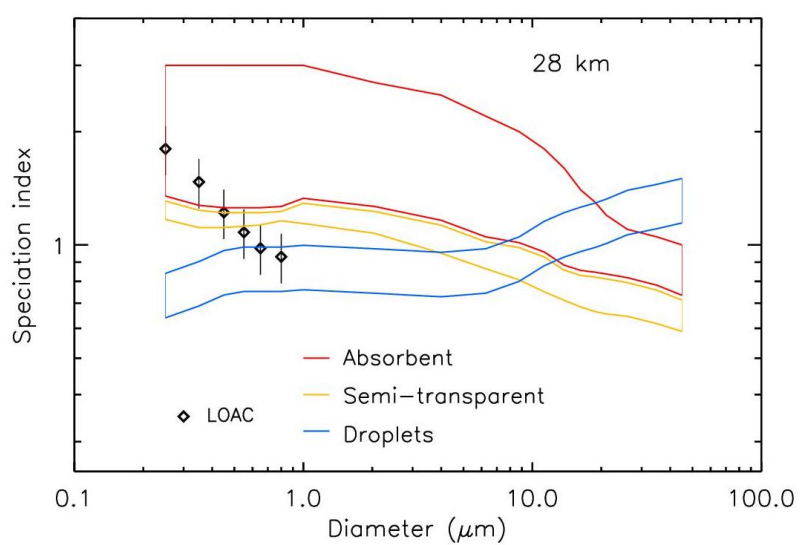

Figure 7: Indications of typologies from the LOAC speciation index in the stratosphere for the 23 November 2017 flight

As a result, within the error bars, we can conclude that LOAC seems to have detected similar concentration enhancements as those previously reported from STAC measurements, although the two instruments use different geometries of observation. About $25 \%$ of the 135 LOAC and 21 STAC flights exhibit such strong enhancements. The enhancements could be sometimes only for submicronic particles, and sometimes for all size classes up to more than $10 \mu \mathrm{m}$. The typology measurements indicate that most of the enhancements are dominated by NSPs particles: nevertheless, the speciation index varies from one flight to another from semi-transparent to strongly absorbent particles, which could indicate that several families of NSPs were detected. To attribute the origin of these detections, it is necessary to review the already published results on NSPs detections obtained by the various instrumental techniques.

\section{Previous studies on the spatial and temporal variability, size and composition of NSPs}

\subsection{Vertical dependence of NSP particles}

In the middle and upper stratosphere, Neely et al. (2011) have compared the SAGE II satellite extinctions to model calculation (WACCM) assuming only liquid aerosols. They have found strong enhancement of measured extinction above $30 \mathrm{~km}$ altitude on average; a mean extinction value of about $5.10^{-6} \mathrm{~km}^{-1}$ is found at $40 \mathrm{~km}$ altitude although model calculations provide a zero value for sulfate aerosols. The extinction enhancements are associated with the contribution of meteoritic smoke particles, coming from the disintegration of meteorites or micrometeorites and recondensation processes (Plane, 2003; Plane et al., 2018; Rapp et al., 2007; Bardeen et al., 2008; Plane, 2012), while an external and/or internal mixture of smoke particles and sulfate aerosols occur at lower altitudes. The ubiquitous presence of non-optically transparent particles was also found in the extinction measurement by 
GOMOS/Envisat, at the same altitudes as SAGE II, for which the wavelength dependence of the extinction strongly differed from the one expected for liquid aerosols only (Salazar et al., 2013). The presence of light-absorbing particles in the middle stratosphere was also detected from sparse balloon measurements with extinctions and radiance measurements (Renard et al., 2005; Renard et al., 2008); these particles could be either internally or externally-mixed with the sulfate aerosols. Nevertheless, such remote sensing measurements do not provide the precise nature and composition of these particles, socalled "soot" by the authors although "strongly optically-absorbing material" could be more appropriate (the terminology for describing such light-absorbing carbons is reviewed in Bond and Bergstrom (2007)).

The presence of soot and $\mathrm{BC}$ in the lower stratosphere was detected below $20 \mathrm{~km}$ altitude using wire impactors on airplane (Pueschel et al., 1992; Blake and Kato, 1995; Strawa et al., 1999). According to Strawa et al. (1999), BC aerosol number density could be of about $1 \%$ of the total aerosols content in the lower stratosphere. On the other hand, Baumgardner et al. (2004) have studied the concentration of light-absorbing particles (attributed to $\mathrm{BC}$ and particles with metals) in the 0.2-0.8 $\mu \mathrm{m}$ size range above the tropopause in the northern polar vortex by light scattering and incandescence measurements, and found more than 10 particles $\mathrm{cm}^{-3}$ in that size range. These light absorbing particles are more concentrated by a factor of 10 than the non-light absorbing particles below $0.3 \mu \mathrm{m}$ inside the polar vortex, with higher contents than for extra-vortex air. Similarly, by using counting techniques and heating to remove the volatile material, Curtius et al. (2005) found a much higher fraction of particles containing non-volatile residues inside than outside the polar vortex. These particles could result from the downward transport of refractory meteoritic material within the polar vortex from the mesosphere to the lower stratosphere as concluded from aerosol collections (Weigel et al., 2014; Ebert et al., 2016).

At other latitudes, Murphy et al. $(2007,2014)$ have derived two categories of NSPs for altitudes below $20 \mathrm{~km}$ at different latitudes, using Particle Analysis by Laser Mass Spectrometry (PALMS) observations: NSP with metal compounds proposed to probably originate from vaporized and condensed meteoritic material, and NSP with mixture of sulfate and organic particles. The second category corresponds to the main components of aerosols in the mid-latitude and tropical lower stratosphere. These observations agree with the Schwarz et al. (2006) results in the northern tropical region, where $40 \%$ of BC particles showed evidence of internal mixing. Then, the average fraction of carbonaceous material in the stratospheric particles decreases rapidly with increasing altitude.

\subsection{Sporadic strong enhancements in the stratospheric aerosol content from NSPs}

Several authors have reported local enhancements of NSP concentrations in the stratosphere. These sporadic features are highly variable in term of residence times (i.e. from the scale of days to months).

Jost et al. (2004) have detected plumes of carbonaceous particles originating from North American forest burning in July 2002 up to an altitude of $16 \mathrm{~km}$ by Laser Mass spectrometry and counting measurement. The increase concentration is about 7 times higher than background conditions. The origin of the particles was confirmed with correlated CO measurements. Short-living and local increases up to a factor 2.5 in aerosol extinction measurements related to intense biomass burning have been seen by the SAGE III space- 
borne instrument over Australia at the beginning of 2003 (Fromm et al. 2006). These particles can be injected in the lower stratosphere by the pyroconvection process occurring at the top of the dense smoke clouds (Fromm and Servranckx, 2003). Ground-based lidar measurements at Observatoire de Haute Provence, France $\left(43.9^{\circ} \mathrm{N}, 5.7^{\circ} \mathrm{E}\right)$ and space-borne lidar measurements from the CALIOP/Calipso instrument have detected plumes of fire particles between 18 and $20 \mathrm{~km}$ altitude over southern France, coming from wildfires in northwest Canada and United States in August 2017 (Khaykin et al., 2018). The scattering ratio at $532 \mathrm{~nm}$ wavelength is about 10 times higher than for background conditions. Also, a layer of soot particles at $15-16 \mathrm{~km}$ altitude coming from these wildfires, and well identified by the specific wavelength dependence of the lidar depolarization ratios, were observed in Germany over Leipzig $\left(51.3^{\circ} \mathrm{N}, 12.4^{\circ}\right.$ ) on 22 August 2017 (Haarig et al., 2018). These measurements have shown that local enhancements of fire plume particles can be detected several thousands of $\mathrm{km}$ from their sources, impacting the stratospheric aerosol content at the hemispheric scale, with an amplitude (both in terms of aerosol content and residence time) comparable to that of a moderate volcanic eruption (Peterson et al., 2018). Satellite data show that the NSPs from this specific fire plume event remained detectable in the northern hemisphere stratosphere over a period of about 8 months (Kloss et al., 2019). Nevertheless, the morphology and composition of these particles have not been determined so far.

Local intrusions of particles attributed to $B C$ have also been reported from CALIOP/Calipso in the lower stratosphere during the monsoon season over India, with few sparse enhancements by 20-30 km altitude (Govardhan et al., 2017). The origin of such particles is not well-established though these authors propose them to originate from airplanes traffic before being vertically transported.

Moderate volcanic eruptions can inject aerosols directly into the lower stratosphere. Some ashes can be present, as observed after the Kelud eruption (February 2014) in the lower tropical stratosphere (Vernier et al., 2016). Ashes were detected by analysis of CALIOP/Calipso space-borne observation in comparison with in situ measurements from optical backscatter aerosols sounders and optical aerosols counters. The residence time of ash material in the stratosphere depends on the injection altitude and on the size of the particles. Values of several weeks are expected due to sedimentation (Niemeier et al., 2009). However, the residence time of ash material is not clearly determined especially when mixing or coating processes with sulfate occur.

Rockets produce solid particles that can be found in the stratosphere. Campaigns of in-situ particle counter measurements were conducted on board airplanes in 1996 and 1997 to detect the alumina particles in the motor exhaust plumes. Measurements in the stratosphere between 17 and $19.5 \mathrm{~km}$ showed strong concentration enhancements of about a factor of 100 with respect to the nearby background conditions (Ross et al., 1999).

The ground-based twilight photometric observations have shown accumulation layers at altitudes of $30 \mathrm{~km}$ and $54 \mathrm{~km}$ on 20-21 November 1998 during the Leonids meteor shower (Mateshvili et al., 1999). Large and thin dust accumulation layers were also detected between 20 and $50 \mathrm{~km}$ altitude on 21-26 November 2001, 25-27 November 2002, and 16-17 November 2003 during the Leonids (Padma Kumari et al., 2005). The Leonids, as opposed to permanent meteor showers visible on every year at a given epoch, may produce periodic meteor storms, for about 3 to 4 years, every 33 years, in November. The enhancements in the twilight light intensities are of tens of percent. Such layers were observed 4 to 8 days after the peak meteor activity, but with a strong variability from one day to another for the 
altitude and the amplitude of the vertical structures. The authors state that, a couple of weeks after the meteor activity, the atmosphere had recovered its normal dust distribution profile although a dust layer at $30 \mathrm{~km}$ altitude could have persisted. Such observations of transient layers need to be confirmed for other occasional and major meteor storms.

Some lidar observations in the Arctic during the 2000-2001 winter have fortuitously detected strong concentration enhancements from 25 to $40 \mathrm{~km}$ altitude, with strong spatial and temporal variability over a few days (Gerding et al., 2003). It has been proposed that they could originate from meteoritic debris after the disintegration of a meteoroid in the atmosphere or from debris of condensed rocket fuel. Klekociuk et al. (2005) have also observed a strong particle enhancement around $30 \mathrm{~km}$ altitude, which was well identified as coming from the disintegration of a large meteoroid of a few meters in size on 3 September 2004 over Antarctica, with residence time from weeks to months.

Major meteoritic disintegrations can produce strong enhancements in aerosol concentrations, initially localized at the altitude of the disintegration and then progressively dispersed by the global circulation. The Chelyabinsk meteor event on 15 February 2013 started with an enhanced aerosol loading in the 30-35 km altitude range, as seen in extinction measurements of the OSIRIS/ODIN satellite instrument (Rieger et al., 2014). OMPS instrument onboard the Suomi NPP spacecraft has detected an extinction enhancement of a factor 10 at $40 \mathrm{~km}$ altitude and a few $\mathrm{km}$ width. It has also monitored the motion of the associated ring-shaped plume in the mid-latitude stratosphere, over at least 3 months, through its dispersion and its sedimentation from 40 to $30 \mathrm{~km}$ altitude (Gorkavyi et al., 2013).

Such local concentration enhancements in the middle stratosphere, at least 5 to 100 times higher than background levels, have been occasionally detected by the balloon-borne Stratospheric and Tropospheric Aerosols Counter (STAC) having operated from 2003 to 2011 (21 flights) at various latitudes (Renard et al., 2008; Renard et al., 2010). Such enhancements were mostly detected in the middle stratosphere. Although the instrument has not been designed to distinguish between liquid and optically-absorbing particles in terms of sizing, particles up to $5 \mu \mathrm{m}$ were detected in some enhancements, unlikely to be pure sulfuric acid aerosols at such altitudes. In particular, 8 STAC flights were conducted above northern Sweden from 2 August to 7 September 2009, showing a strong variability from one day to another of the aerosol content and transient enhancements in the middle stratosphere (Renard et al., 2010). The enhancements could be very local, i.e. of a few $\mathrm{km}$ in term of horizontal extent (Renard et al. 2008).

\subsection{Size distribution}

The size distributions of NSPs in the stratosphere are poorly estimated. Indications have been mainly obtained by optical counters and by in-situ collectors with analyses by electron microscopy at ground.

Hunten et al. (1980), combining modeling calculations of the meteorite ablation around $80 \mathrm{~km}$ altitude and airplane collected particles (Brownlee, 1978), has proposed a bimodal repartition of the solid material in the middle stratosphere. The particles below 0.1 $\mu \mathrm{m}$ could come from the descending smoke particles, while the largest particles could originate from interplanetary dust and meteoritic debris. Nevertheless, the real content of NSPs could be more complex. 
In the lower stratosphere, different size distributions have been detected. In the Arctic, the optically-absorbing particles can dominate for size below $0.3 \mu \mathrm{m}$ (Baumgardner et al., 2004), The rocket engine plumes measurements, for the two cases-studies in the 17-19.5 $\mathrm{km}$ altitude range, have shown a three modal distribution centered below $0.01 \mu \mathrm{m}$, around $0.1 \mu \mathrm{m}$ and around $2 \mu \mathrm{m}$ (Ross et al., 1999). The fine volcanic ashes in the lower tropical stratosphere after the Kelud eruption have been estimated to be below $0.6 \mu \mathrm{m}$ in optical diameter (Vernier et al., 2016). The PALMS instrument, which has detected two families of NSPs in the lower stratosphere, has shown that the particles have an aerodynamical diameter below $1 \mu \mathrm{m}$ (Murphy et al. 2014). However, the instrument works only in the 0.2-2 $\mu \mathrm{m}$ size range and the aerodynamical diameter can significantly differ from the optical diameter used by the optical aerosol counters.

The particles collected from airplanes present a wide variety of shapes and sizes. Soot particles are in general smaller than $1 \mu \mathrm{m}$, in a compact or chain-like shapes (Pueschel et al., 1992; Blake and Kato, 1995; Strawa et al., 1999). Submicronic to 10- $\mu \mathrm{m}$ particles of very different shapes and natures were collected by Ebert et al. (2016) in the stratospheric polar vortex at altitudes up to $21 \mathrm{~km}$ (Figure 8). Large particles, from a few $\mu \mathrm{m}$ to a few tens of $\mu \mathrm{m}$, are also present in the NASA aircraft JSC dust collections (Jessberger et al., 2001; Sandford et al., 2016) and in the balloon-borne dust collection by the DUSTER instrument (Ciucci et al., 2008). The concentrations of particles greater than a few $\mu \mathrm{m}$ could be in the $10^{-6}-10^{-3}$ particles $\mathrm{cm}^{-3}$ range.

\subsection{Particles chemical composition}

In the lower stratosphere, the presence of an aerosol population with mixed sulfuric acid and metals, principally $\mathrm{Fe}, \mathrm{Na}, \mathrm{K}, \mathrm{Al}, \mathrm{Cr}$, Ni atoms, has been derived from airborne massspectrometry observations (Murphy et al., 1998; 2014). Soot or BC particles have been also detected, in agreement with other observations (Blake and Kato, 1995; Strawa et al., 1999). Also, Scott and Chittenden (1993) have shown from collected particles that the composition of particles below $0.2 \mu \mathrm{m}$ strongly differs from that of the common pure sulfate aerosols; the main population of these ultrafine particles is composed of carbon, with traces of $\mathrm{S}, \mathrm{Na}$, metal sulfates and chlorides.

The analysis of hundreds of airplane-collected NSPs in the polar winter lower stratosphere by Ebert et al. (2016) has shown that refractory particles greater than $0.5 \mu \mathrm{m}$ mostly consist of silicate, silicate/carbon mixtures, Fe-rich, Ca-rich, and complex metal mixtures including aluminum. The detection of metallic spheres within some mixed particles might indicate the effect of high temperatures during the formation process but is not in line with the results from airborne mass spectrometers which might rather suggest diluted Fe atoms (Murphy et al., 2014). On the other hand, particles below $0.5 \mu \mathrm{m}$ are mostly composed of soot (Ebert et al., 2016). Most of these submicronic carbonaceous refractory particles are completely amorphous and only a few particles are ordered with graphene sheets (Schütze et al., 2017); minor traces of $\mathrm{Si}, \mathrm{Fe}, \mathrm{Cr}$, Ni are often found in these carbonaceous particles, and no difference has been highlighted in terms of size, nanostructure and elemental composition for such particles either collected inside and outside the polar vortex at least for the period of these observations, i.e. winter 2010. 


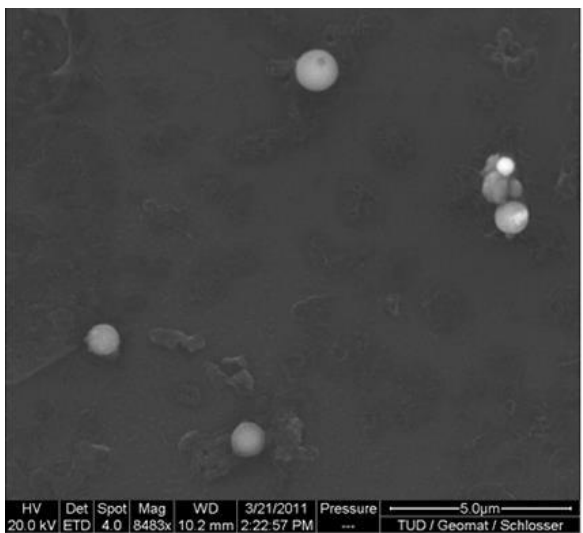

(a)

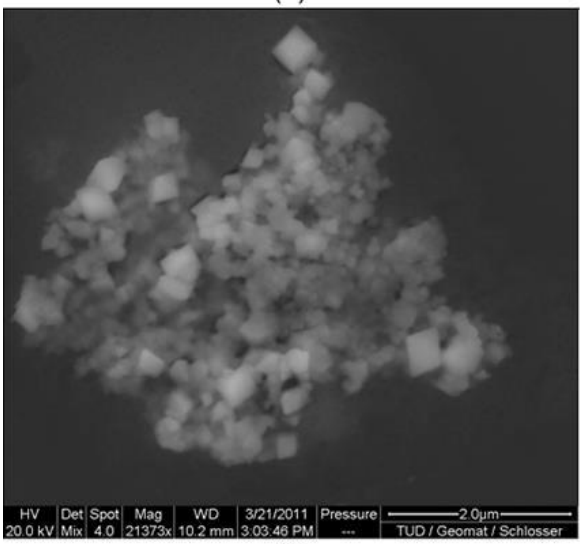

(c)

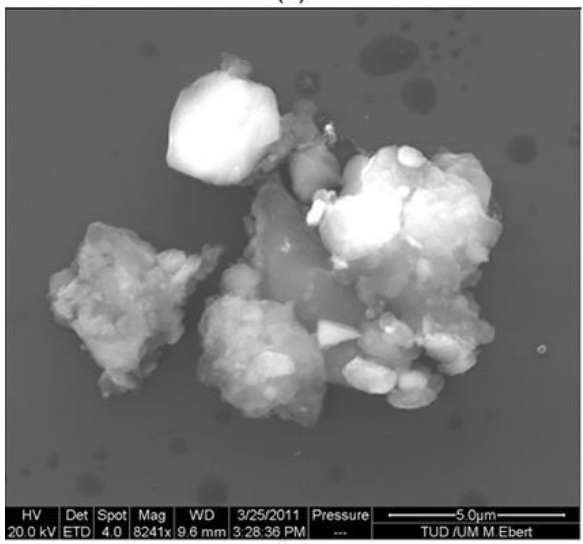

(e)

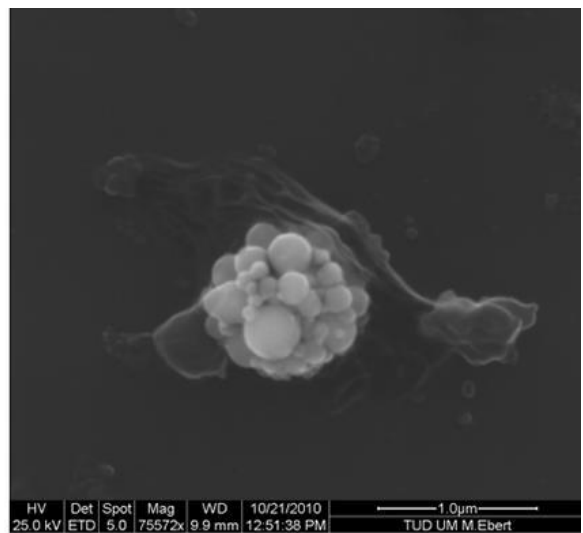

(b)

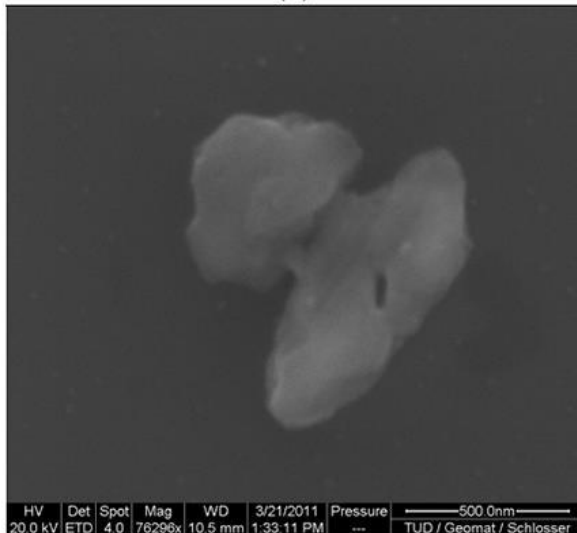

(d)

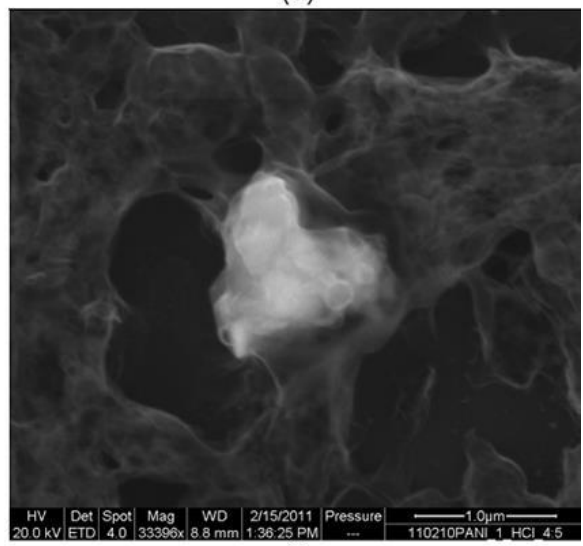

(f)

Figure 8: Examples of particles collected from an airplane (Figure 3 of Ebert et al. 2016), showing their diversity in size, morphology and composition. The electron-microscope images present refractory particles of (a) silicate spheres, (b) Fe-rich particle; (c) complex metallic mixture ( $\mathrm{Al} / \mathrm{Cr} / \mathrm{Mn} / \mathrm{Fe}$ ), (d) Ca-rich particle, (e) carbon /silicate mixture, and (f) silicate particle 
Amongst the huge number of particles collected by the NASA airplane in the lower stratosphere, particles assumed to be chondritic porous interplanetary dust, also named CP IDPs, are composed of optically black aggregates of submicron components, with a wide range of porosities (Rietmeijer, 1998). They are significantly enriched in carbon, most likely in the form of pristine and complex organic molecules (Thomas et al., 1993; Flynn et al., 2013; Koschny et al. 2019). Similarities between these particles and cometary dust particles have been progressively suggested by analyses of samples from the Stardust flyby mission at comet 81P/Wild 2 (Ishii et al., 2008), and more recently established through results on the composition and the physical properties of cometary dust from the long-duration Rosetta mission with comet 67P/Churyumov-Gerasimenko (Levasseur-Regourd et al., 2018; Mannel et al. 2019). Also, the carbonaceous micrometeorites collected in Antarctica, also named UCAMMs for Ultra Carbonaceous Antarctica Micro-Meteorites (Engrand and Maurette, 1998), after partial survival to the atmospheric entry and thus short transit in the stratosphere, are estimated to be of cometary origin with up to $85 \%$ of organic matter in volume (Nakamura et al., 2005; Dartois et al., 2018; Levasseur-Regourd et al., 2018) mixed with tiny flakes of minerals.

In the middle stratosphere, Testa et al. (1990) have found $\mathrm{Cl}, \mathrm{S}, \mathrm{Ti}, \mathrm{Fe}, \mathrm{Br}, \mathrm{Ni}, \mathrm{Zr}, \mathrm{Zn}$, $\mathrm{Sr}$, and $\mathrm{Cu}$ elements to be present in the aerosols (elements having atomic number lower than 16 could not be detected in their analysis), with $2 / 3$ of the 23 analyzed non-graphitic particles ranging from $\mathrm{Al}$ rich silicates to almost pure $\mathrm{Fe}$, and one particle consisting-almost exclusively of $\mathrm{Ba}$ and S. The DUSTER collection has shown also two $100 \mu \mathrm{m}$ spheres with OSi-Na-Mg-Ca composition (Ciucci et al., 2008) and the presence of pure carbon particles, aggregates of $\mathrm{CaCO}$ and $\mathrm{CaCO}_{3}$ grains (Della Corte et al., 2013).

\section{Sources from ground to space}

\subsection{Context}

All the information derived from the previously described reported studies appears difficult to reconcile in terms of NSP concentrations, size distributions, and compositions. In fact, most of the measurements could represent snapshots on specific geophysical conditions. The strong vertical, temporal and typology variabilities of NSPs detected by LOAC from one flight to another over a 6-year period seem to confirm the complexity of the stratospheric NSP content and the difficulty to propose a global view of particles' origins.

Multiple sporadic and permanent sources of NSPs must be considered, coming from Earth (emitted from the surface or produced within the atmosphere) and from space. In particular, some authors have mentioned (disintegrated) meteoritic material, which is indeed a source, but did not always consider porous carbonaceous interplanetary dust particles as mainly originating from comets on prograde orbits. The grains resulting from meteoritic disintegration could differ in size, shape and composition of those coming from the interplanetary dust cloud. The recent results of the Rosetta mission on comet 67P/Churyumov-Gerasimenko have provided a ground-truth for such particles.

We present below the different sources of the NSPs from ground to space that can be found within the stratosphere. The table 1 summarizes the main characterizes of such particles. 


\begin{tabular}{|c|c|c|c|}
\hline Nature & Typical size & Source & Origin \\
\hline \hline Volcanic ashes & $<0.6 \mu \mathrm{m}$ & From ground & Natural \\
\hline Biomass burning & $<1 \mu \mathrm{m}$ & From ground & Natural \\
\hline Pollution & $<1 \mu \mathrm{m}$ & From ground & Anthropogenic \\
\hline Polymeric nanocomposites & $>1 \mu \mathrm{m}$ & Produced in the atmosphere & Natural \\
\hline Rocket exhaust plume & $<5 \mu \mathrm{m}$ & Produced in the atmosphere & Anthropogenic \\
\hline Airplane soot & $<1 \mu \mathrm{m}$ & Produced in the atmosphere & Anthropogenic \\
\hline Meteoritic disintegration & All sizes & $\begin{array}{c}\text { From space and produced in } \\
\text { the atmosphere }\end{array}$ & Natural \\
\hline Satellite disintegration & All sizes & $\begin{array}{c}\text { From space and produced in } \\
\text { the atmosphere }\end{array}$ & Anthropogenic \\
\hline Interplanetary / cometary dust & $<1 \mathrm{~m}$ & From space & Natural \\
\hline
\end{tabular}

Table 1: Summary of the various sources of NSPs

\subsection{Sources from Earth's surface}

The presence of volcanic ashes in the stratosphere associated with some volcanic eruptions is due to an explosive process injecting directly the material into the stratosphere. No mechanism of injection of ashes in the troposphere with subsequent transport to the stratosphere by the Brewer-Dobson circulation has been reported so far.

Major biomass burning and organic fuel burning, having natural or anthropogenic origin, are more frequent and can produce thick clouds of carbonaceous particles that can reach the tropopause level. These particles can reach the lower stratosphere through direct injection by cross-tropopause pyroconvection events or through transport of fire plumes associated with overshooting convective systems (Damoah et al., 2006; Fromm et al., 2005; de Laat et al., 2012). Also, they might be injected directly in the stratosphere through the tropopause folds at tropical latitudes.

In addition to these sporadic events, periodic atmospheric mechanisms can consist in a source of NSPs at a global scale. In particular, the Asian summer monsoon and the associated Asian Monsoon Anticyclone (AMA) largely determine the composition of the Upper Troposphere / Lower Stratosphere (UTLS). An accumulation of aerosols has been pointed out inside the AMA and is present each year from June to September in the 15-18 $\mathrm{km}$ altitude range in the UTLS region. This layer, known as the Asian Tropopause Aerosol Layer (ATAL) (e.g. Vernier et al., 2018), is likely to be associated with Asian emissions of anthropogenic pollutants like sulfur dioxide and volatile organic compounds, building a population of NSPs consisting of a mixture of sulfates and organic material both as primary and secondary organic aerosols. The ATAL is sustained by the convective activity of the Asian monsoon as indicated by global model simulations (Yu et al., 2015; Fadnavis et al., 2017). However, the precise composition, variability, trend and budget of the ATAL are still largely uncertain and are currently under investigation. After the breakup of the AMA, the signature of the ATAL is detectable on the extratropical aerosol budget in the northern hemisphere 
(Khaykin et al., 2017) indicating that combined processes, i.e. emissions in Asia, convective activity and general circulation, impact part of the global stratospheric NSP population.

\subsection{Production within the atmosphere}

If soot particles emitted from airplane engines can be directly injected in the lower stratosphere during their cruise, their contribution is expected to be low with respect to other sources coming from natural and anthropogenic biomass burning (Baumgardner et al., 2004; Hendricks et al., 2004; Schwarz et al., 2006), although the air traffic is increasing.

Hypothetical long-lived volcanic soot particles could be also produced in the stratosphere due to thermal decomposition of methane in the volcano eruption column (Zuev et al., 2014, 2015), but this process need further studies and confirmation.

The rockets exhaust and the disintegration of satellites subsequently to their entry in the Earth's atmosphere produce locally alumina, hydrocarbon and metallic debris (Ross et al., 1999; Cziczo et al., 2002. The local content of these specific refractory NSPs increases whenever measurements are fortuitously conducted inside a plume (Newman et al., 2001). Such particles can be also collected far from their sources at different times of their transit in the atmosphere during which their physical properties are likely to evolve. As a result, some of them have been found to be mixed with particles having other origins (Ebert et el., 2016).

Compact particles and filaments having 5-10 $\mu \mathrm{m}$ in size and up to several $\mathrm{mm}$ long, composed of carbon polymeric nanocomposites, can be produced in ambient air inside plasmas (Hamdan et al., 2017). Such conditions occur during atmospheric entries of meteorites and satellites/rocket debris and during storm lightning (Courty and Martinez, 2015) and perhaps during high-energy phenomena in the stratosphere such as blue jets and sprites. These nanocomposites are characterized by the presence of Fe-Ni-Cr elements. Some of the grains collected by Ebert et al. (2016) present the same composition and could be nanocomposites produced within the atmosphere instead of meteoritic material. Also, dusty plasma spherical particles typically in the 0.1-1.5 $\mu \mathrm{m}$ size range can be produced in glow discharge (Pereira et al., 2005) as those encountered in the atmosphere. Layers of such particles (spheres and filaments) could produce significant local concentration enhancements of micron(s)-sized aerosols.

The rare events of the disintegration of large meteoroids, with sizes above about 10 $\mathrm{m}$, occur several times per century and can produce a large plume of dust that can take months to sediment, as for the Chelyabinsk meteor in February 2013. Disintegration of meter-sized meteoroids is detected several times per year and can produce local layers of dust. And partial or total disintegration of $\mathrm{cm}$-size meteoroids could occur daily. The disintegration altitude depends on the velocity entry, the incidence angle of the trajectory, the density and the composition of the meteoroid (minerals like olivine, iron, ices, complex organics; e. g. Fortov et al., 2013; Coulson et al., 2014). The probability of crossing such a layer fortuitously during in-situ measurements is very low but non-negligible.

Meteoritic ablation may begin by altitudes of about $180 \mathrm{~km}$. Layers of minerals and metals are then present in thermosphere between 100 and $80 \mathrm{~km}$ altitude from the recondensation process (Rapp et al., 2007; Bardeen et al., 2008; Plane, 2012) that produce nanometer-sized smoke particles (Antonsen et al., 2017). Such NSPs need to be aggregated or to grow through the condensation of sulfuric acid when transported downward to produce particles of at least of $150 \mathrm{~nm}$ to be optically detectable by optical aerosol counters. 


\subsection{Dust from space}

The Earth orbits around the Sun within the interplanetary dust cloud, which is a wide and flattened circumsolar cloud built of dust particles (e.g. Koschny et al. 2019). Their sizes range from a few tens of $\mathrm{nm}$ to a few decimeters, with dominant sizes around hundreds of $\mu \mathrm{m}$. The spatial density of the interplanetary dust cloud increases towards the Sun and its near-ecliptic symmetry surface, although it remains extremely low, with about 5 to 20 particles of about 10 about $\mu \mathrm{m}$ size per $\mathrm{km}^{3}$ in the vicinity of the Earth (e. g. LevasseurRegourd et al., 2001).

Since particles within such a size range slowly spiral towards the Sun (under PoyntingRobertson effect), the existence of the interplanetary dust cloud indicates that a more or less continuous replenishment takes place. Interpretation of observations in the visible and infrared domains (Lasue et al, 2007; Rowan-Robinson and May, 2013) and dynamical studies (Nesvorny et al., 2010) indicate that most of the interplanetary dust particles reaching the Earth's vicinity are of cometary origin, with a contribution of about $85 \%$ of the total mass influx from short-period comets with a prograde motion, called JFCs (Jupiter Family Comets).

Dust particles of cometary origin have long been understood to form meteoroid streams, such as the August Perseids from comet 109P/Swift-Tuttle. Besides, infrared observations have allowed the discovery of faint dust bands, attributed to collisions within the asteroid belt (Dermott et al., 1984) and of narrow and elongated structures (so-called dust trails) along JFCs (Sykes et al. 1986; Reach et al. 2007), produced by the ejection of large dust particles or peebles from cometary nuclei.

Because of its sources of replenishment, the interplanetary dust cloud is not a featureless structure (e. g. Levasseur and Blamont, 1973), although dust particles freshly injected are progressively randomly distributed into the cloud. Whenever interplanetary dust particles impact the atmosphere, they induce the formation of sporadic meteors, meteor showers, or even meteor storms (from fresher dust particles in the cloud) that present a strong temporal and spatial heterogeneity. The flux of entry particles can be tens to hundreds of times higher than during background conditions during the main permanent meteor shower episodes; four main events may be mentioned, the Quadrantids (beginning of January), the Aquarids (beginning of May), the Perseids (mid-August) and the Geminids (mid-December)

As already suspected from comet 1P/Halley flybys in 1986, and established by the Rosetta mission with 67P/Churyumov-Gerasimenko in 2014-2016, the refractory component in comets is rich in high molecular-mass organics, possibly about $45 \%$ in mass and $70 \%$ in volume (Bardyn et al., 2017; Herique et al., 2017; Levasseur-Regourd et al. 2018); the flux of exogenous material from interplanetary dust entering in the Earth atmosphere is thus rich in complex organics. The dust particles ejected from the nucleus of 67P/ChuryumovGerasimenko are porous aggregates covering a wide range of sizes, at least from tens to hundreds of $\mu \mathrm{m}$ (Merouane et al., 2016), and of porosities with likely fractal structures (Langevin et al. 2016; Mannel et al. 2016; 2019). Considering the prevalence influx of dust particles originating from JFCs, the speeds of interplanetary dust particles impacting the Earth's atmosphere are mostly low, around 15 km/s range (Nesvorný et al., 2010) or less. Both the relative velocity and the morphology of these porous dust particles should enable 
the survival of significant amounts of cometary organics within the atmosphere (LevasseurRegourd and Lasue, 2011).

The total amount of material entering the Earth atmosphere is still not well determined, with a daily value in the 5-270 tons range depending of the various techniques used for the determination (Plane, 2012); a mean value of about 100 tons per day is frequently assumed (e.g. Rietmeijer, 1998). Carrillo-Sánchez et al. (2016) have considered the cosmic spherule accretion rate at South Pole, the $\mathrm{Na}$ and Fe flux measured in the upper mesosphere coming from the ablation of the incoming solid material, and the satellite measurements of the interplanetary dust cloud radiation. Using ablation-modeling calculations, they have proposed that dust coming from the JFCs contribute to about $80 \pm 17 \%$ of the dust mass entering the Earth atmosphere estimated at $43 \pm 14$ tons per day. A large fraction of NSPs commonly assumed to have a meteoritic origin could in fact originate from comets. Thus, it can be suggested that the aggregated porous and complex organicsrich particles detected in the stratosphere (Ebert et al., 2016; Schutze et al., 2017) could come from comets, not from asteroids, while silicates-rich particles could come either from comets or asteroids.

Nevertheless, two difficulties may arise for the detection and the identification of the incoming material and the identification of their origin (cometary dust or meteoroid disintegration in the atmosphere). First, some dust particles may be broken during their atmospheric travel, producing a significant number of smaller particles, some of them being not detectable. Secondly, carbonaceous particles might originate either from space or from Earth. Thus, some layers of concentration enhancements could be produced for particles with similar physically properties as the terrestrial ones but originating from space.

\section{Origin of stratospheric concentration enhancements and transport mechanisms}

We discuss here how LOAC particle counter observations under weather balloons could help to better understand the origin and the transport of the NSPs leading to concentration enhancements in the stratosphere.

The enhancements reported by various authors were observed sometimes during well-known meteor shower periods but also apart from these events. As said before, about $25 \%$ of the 135 LOAC and 21 STAC flights exhibit strong enhancements. Such a probability seems to be too high for fortuitous detections of meteoritic disintegrations or of fragmentation of large interplanetary dust.

Figure 9 presents the number of concentrations enhancements per flight per week for all the STAC and LOAC balloon flights as a function of the day of the year. The main meteor showers are represented by dotted lines (the thickness of lines is related to the intensity of the episode). No obvious correlation is statistically detected between the variability of the number events and the meteor shower dates and intensities, although some fortuitous coincidence can exist. Then, it can be concluded that the concentrations enhancements in the stratosphere are not directly related to the meteor showers. 


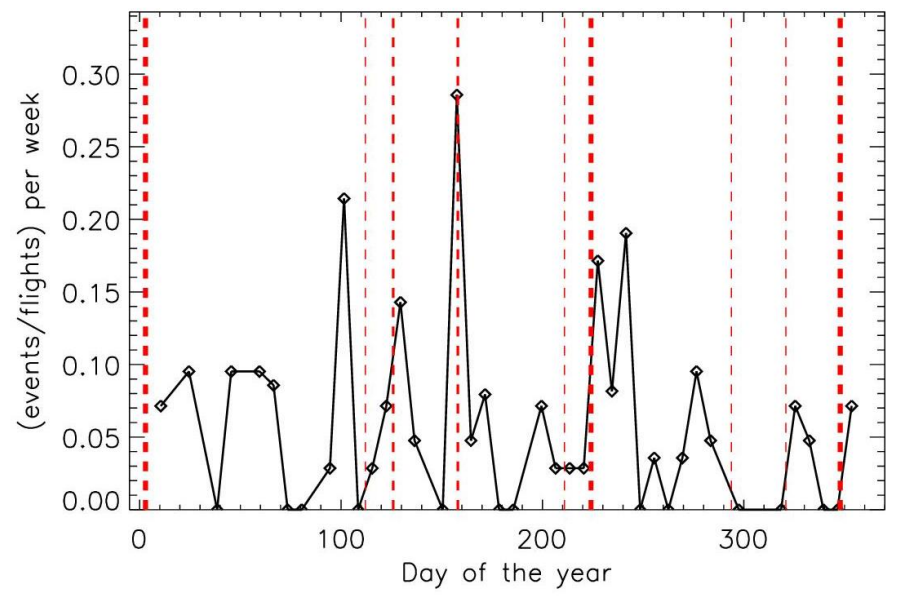

Figure 9: Number of concentrations enhancement per flight per week, for all the LOAC and STAC measurements during balloon flights; the red dotted lines represent the main meteor showers episodes (the thickness of the dotted lines is related to the intensity of the episode)

Different dynamical processes may explain the concentration enhancements. A process differing from the common atmospheric transport mechanisms, the gravitophotophoretic effect (Rohatschek, 1996; Pueschel et al., 2000) could allow light-absorbing particles (like BC) to be lifted until the gravity counteracts their ascent, which could explain transport of carbonaceous particles higher up in stratosphere, as for the 2017 Canadian wildfires (Ansmann et al., 2018; Haarig et al., 2018). Such carbonaceous aerosols could stay for several months at the hemispheric scale for these specific events (Kloss et al., 2019) or be present ubiquitously in the tropical lower stratosphere (Murphy et al., 2007; 2014).

For particles of any nature, as proposed by Beresnev et al. (2012), vertical winds in the stratosphere could be the basic force mechanism rather than gravito-photophoresis for the formation and the spatial and temporal stability of aerosol layers (Gryazin et al., 2011). The vertical winds could provide a levitation of the particles in the stratosphere and could form spatial dynamical traps, in which aerosols are compelled to be in form of thin layers. The averaged vertical wind could be the strong competitor of turbulent diffusion that prevents from the stratification of stratospheric aerosols.

Another process could provide the levitation and the accumulation layers of soot and BC particles: the radiometric photophoresis effect. Improvements in the theoretical works show that accumulation layers of soot and BC particles could exist at different altitudes in the stratosphere, depending on the size and the shape (compact or fractal) of the particles (Beresnev et al., 2017). The larger the particles are, the potentially higher the accumulation layers could be. In a steady-state atmosphere, accumulation layers of submicronic soot can be in the 10-30 km altitude range; soot aggregates of several micrometers could reach $60 \mathrm{~km}$ altitude. But in a non-steady atmosphere, we may expect that these layers are dynamically perturbated and then can disappear.

Finally, strong gravity-wave events could also locally increase the aerosols content and can produce thin layers, as observed one time at mid-latitude with the balloon-borne LOAC (Chane-Ming et al., 2016). 
Some of these phenomena could explain most of the concentration enhancements attributed to NSPS and previously detected by the STAC balloon-borne aerosols counter at different altitudes and locations (Renard et al., 2008, 2010), and also for the sparse enhancements of carbonaceous particles observed by CALIOP/Calipso during the monsoonal convective season over India (Govardhan et al., 2017). Also, they could explain the enhanced concentrations layers detected after Leonids meteor shower events, linked or not to the disintegration of incoming extraterrestrial material. Soot particles can have different size distributions and fractal/compact shape depending on their origin and their aging (e.g. Adachi et al., 2007), which could explain the various altitudes for the detected accumulation layers.

A statistical analysis of the altitude of the concentration enhancement events detected by LOAC seems to indicate a double repartition, one centered at around $17 \mathrm{~km}$ and the second one at around $30 \mathrm{~km}$ (Figure 10). The analysis is conducted by calculating the percentage of events in respect with the total number of measurements available at the various altitudes. This double repartition looks like the one proposed by Beresnev et al. (2017) for the accumulation layers of fractal and spherical carbonaceous particles respectively (which could correspond to porous fractal aggregates and dense aggregates). The LOAC typologies indicate that optically-absorbing particles dominate the aerosolenhanced layers although sulfates are also present. The origin of these particles is unknown, since carbonaceous particles coming from space, produced within the atmosphere and emitted from the Earth's surface can be compact and/or fractal.

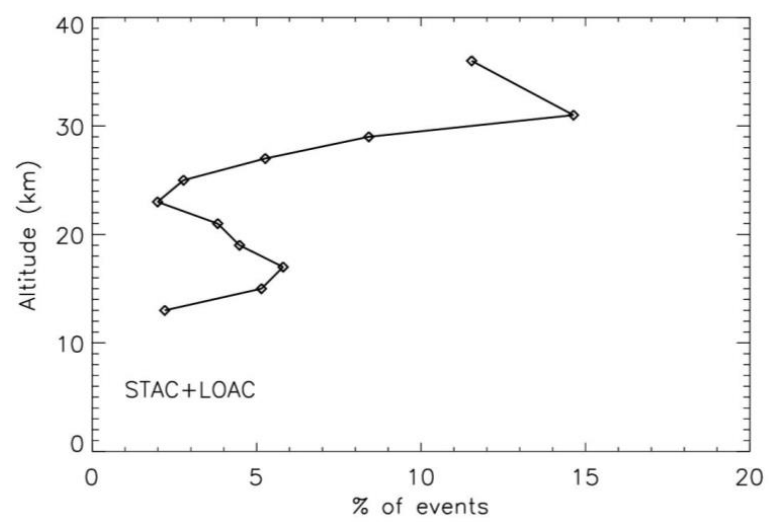

Figure 10: Evolution with altitude of the percentage of concentration enhancement events detected by the STAC and LOAC aerosol counters during balloon flights

\section{Background concentrations for large NSPs}

Finally, LOAC can be used to estimate the background content of large NSPs, with sizes ranging from several $\mu \mathrm{m}$ up to $100 \mu \mathrm{m}$, usually expected to come from space (interplanetary dust and meteoritic debris), with possible growth by sulfuric acid condensation consequently to their descent in the stratosphere (Bardeen et al., 2008).

Considering the number of flights per year, the balloon ascent speed $\left(\sim 5 \mathrm{~m} . \mathrm{s}^{-1}\right)$ and the pump flow ( 2 L. $\mathrm{min}^{-1}$ ), LOAC has sampled about 1 to $2 \mathrm{~m}^{3}$ of air per year in the 15-35 
$\mathrm{km}$ altitude range. Figure 11 presents the mean evolution of the concentrations with altitudes of particles detected for the mid-2013 - mid-2019 period, for three size classes (5$7.5 \mu \mathrm{m}, 10-17.5 \mu \mathrm{m}, 20-100 \mu \mathrm{m}$ ) in layers of $5 \mathrm{~km}$ width; the error bars represent the interannual variability. The concentrations seem to decrease by about of factor two from 15 to $35 \mathrm{~km}$ for the three size classes. In the middle stratosphere, the mean concentrations of particles having sizes of about $5 \mu \mathrm{m}, 10 \mu \mathrm{m}$ and $20 \mu \mathrm{m}$ are of about 50, 10 and below 10 particles $\mathrm{m}^{-3}$, respectively. Although the annual volume of air sampled by LOAC is low, it seems that a tendency could be tentatively pointed out. The lower concentrations values are in the 2017-2018 period (with no particles greater than $10 \mu \mathrm{m}$ in the middle stratosphere), while the higher concentrations values are in the 2015-2016 period.

Ebert et al. (2016) have collected during the RECONCILE campaign inside the polar vortex about $10^{3}$ particles $\mathrm{m}^{-3}$ greater than $3 \mu \mathrm{m}$ in the lower stratosphere (below $21 \mathrm{~km}$ ). On the other hand, Hunten et al. (1980) using the Brownlee (1978) measurements have estimated the concentration of interplanetary dust (or micrometeorites) at $30 \mathrm{~km}$ to be of about $10^{-3}$ particles $\mathrm{m}^{-3}$ for sizes greater than $5 \mu \mathrm{m}$. Finally, the concentration of collected particles greater than $5 \mu \mathrm{m}$ by the DUSTER instrument during one balloon-flight at $38 \mathrm{~km}$ was of about one particle $\mathrm{m}^{-3}$ (Della Corte et al., 2013). The LOAC estimates cover all these values. Although these sparse measurements have sampled a small volume of the stratospheric air, they could indicate a strong variability for the large particle's concentrations.
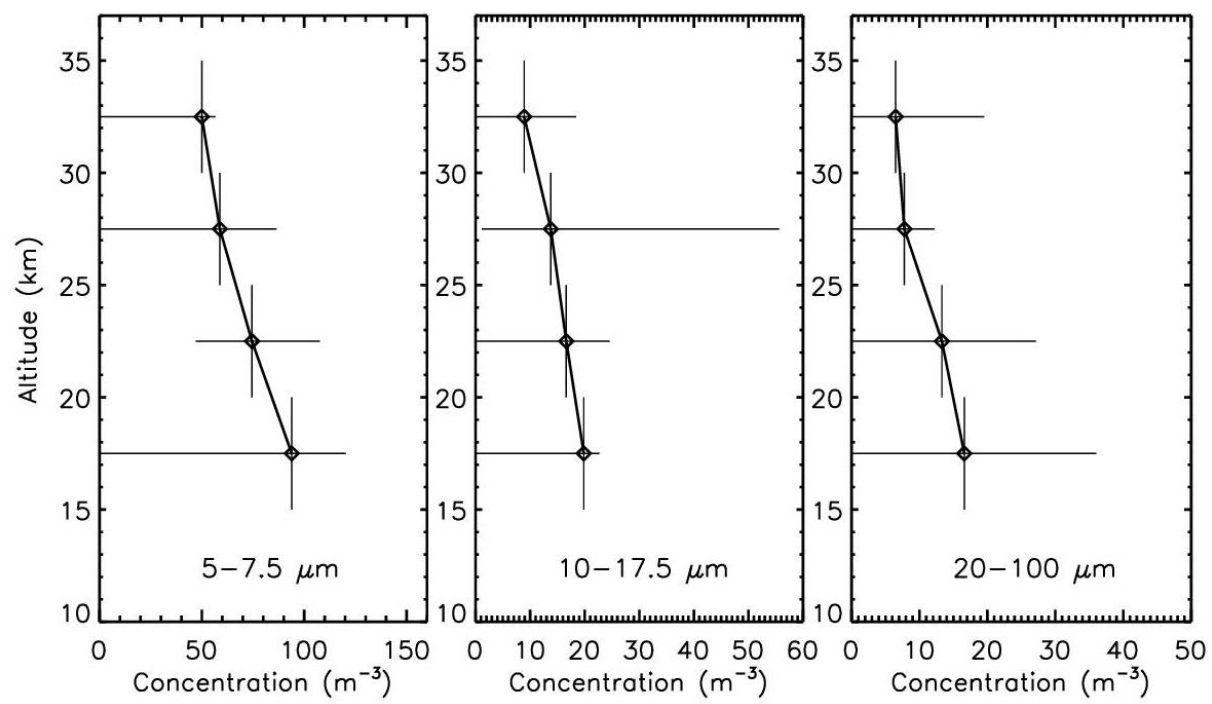

Figure 11: Mean altitude evolutions of the concentrations of the large particles detected by LOAC for the 2013-2019 period, for 3 size classes; the errors bars represent the interannual variability

Some of these particles are often classified as "meteoritic material", based on the presence of $\mathrm{Fe}, \mathrm{Mg}, \mathrm{Ni}, \mathrm{Cr}, \mathrm{Na}$ in their compositions derived from collected samples or from in situ analysis (Cuicci et al., 2008; Ebert et al., 2016). Interplanetary dust, mainly originated from Jupiter Family Comets, must be also considered. Porous cometary dust particles with 
not too high relative velocities happen to reach the stratosphere (Levasseur-Regourd et al., 2018) and about $10 \%$ of the interplanetary dust flux is likely to reach the Earth's surface without suffering any melting (Dobrica et al., 2010); thus, they can contribute to the carbonaceous particles found in the stratosphere. Nevertheless, we may conclude that the presence of interplanetary material in the stratosphere is dramatically overestimated in the litterature, since the detected concentrations are several orders of magnitude above the estimated concentration of material in space at Earth orbit, i. e. $10^{-14}$ particles $\mathrm{cm}^{-3}$ for size greater than $10 \mu \mathrm{m}$ (e. g. Levasseur-Regourd et al., 2001). This last value might be tens or hundreds higher during meteor shower events and even more in case of meteoritic disintegrations inside the stratosphere, but still without reaching the stratospheric concentrations of large NSPs.

We can however propose several explanations for these discrepancies:

- The flux and the size distribution of incoming material from space is strongly underestimated. In particular, the size distribution estimated from impacts on exposed surfaces in space (Mandeville et al., 1991; Love and Brownlee, 1993; Kalashnikova et al., 2000) could be inaccurate and the retrieved diameters and thus the size distribution could differ from those obtained by optical instruments.

- Large fluffy particles (hundreds of $\mu \mathrm{m}$ or greater) entering the Earth atmosphere could undergo breaking processes, producing large number of micron-sized particles and less nanometer-sized (smoke) particles than expected during the ablation processes.

- A space-time sampling bias can be assumed. In other words, the dates and the locations of the in situ measurements could be not fully representative of background conditions, in particular where the regular flights are not well evenly time spaced.

- Some particles produced by the Chelyabinsk meteor disintegration could remain longer than expected in the stratosphere. This could (partly) explain some high concentrations values detected by LOAC since the beginning of the measurements in 2013 until the return to lower values at the beginning of 2017; the low concentration of big particles subsequently to the dilution of the Chelyabinsk meteor cloud in the stratosphere could be undetectable by spaceborne remote-sensing observations.

- The instruments may have mainly detected material coming from the Earth during specific events or produced inside the atmosphere and transported to the middle stratosphere; these particles can remain in some accumulation layers (Beresnev et al., 2012, 2018) and even can agglomerate. We are in favor of this last explanation, since the concentrations decrease with increasing altitudes, and the accumulation layers were indeed detected by the STAC and LOAC aerosols counters at the altitude range predicted by the modelling calculations. Also, the identification of the origin of the particles based on their composition only could be inaccurate. As an example, the nanocomposites produced inside the atmosphere (Courty and Martinez, 2015) could have chemical elements like those found in meteorites or in interplanetary dust.

\section{Conclusions}

Even if a large variety of in situ and remote sensing measurements have been conducted under different atmospheric conditions, none of them can provide a comprehensive view describing the whole complexity of the stratospheric NSP content. The sources are multiple and most of them are non-permanent. One can expect a strong 
variability of the chemical composition, the size and the concentration of stratospheric particles from one session of measurements to another. Also, the particles are likely to be detected or collected at different stages of their life cycle from their emission to their removal from the atmosphere during which they are transformed (e.g. condensational growth, coagulation, inclusion). This complicates the determination of their origin, of their physical properties and of the processes controlling the evolution of their size distributions and concentrations.

The LOAC balloon-borne optical counter has contributed to better understand the origin of the complexity of the NSPs content. It has confirmed the presence of enhanced layers in terms of concentration of submicronic, and sometimes larger, particles in the lower and middle stratosphere. The six years of regular flights (2013-2019) have shown a strong temporal variability of such events, which does not seem to be correlated to the main meteor shower events. At present, the more plausible hypothesis for such spatial and temporal behavior is the presence of accumulation layers of terrestrial and atmospheric particles due to the dynamical and photophoretic effects.

Frequent LOAC balloon flights have shown the necessity to often conduct new systematic stratospheric measurements at various locations to answer the following open questions:

- How to distinguish between the various sources of particles? How to determine their average percentages in terms of size, number concentration and mass, and their evolutions with altitude?

- Are there specific physical and chemical markers allowing to distinguish black carbon and soot particles on a way of formation, types and origins?

- Do most of the complex organic particles are coming from space (e. g. cometary particles) or from the Earth?

- Is there an evolution of the physical and chemical properties of the NSPs in the stratosphere (i.e. aging)?

- Is there an increase of the $\mathrm{BC} /$ soot particles content in the stratosphere due to anthropogenic activities especially in Asia?

- How long is the residence time of NSPs, depending on their origin and the different levitation processes involved?

- Are the local concentration enhancements really accumulation layers coming from the vertical winds and photophoretic processes?

- Is there a direct link between (charged) NSPs and high-energy phenomena above thunderstorms?

- Finally, what are the consequences of the presence of such particles on Earth's radiative balance and on the stratospheric chemistry?

Current aerosols counters cannot be used alone to answer these questions, thus new light instrumentation will be needed, using for instance mass-spectrometers and collecting devices for frequent and low-cost flights. Also, an optical instrument performing measurements at several scattering angles could be useful to better evaluate the mean composition of the particles, as done for example at ground with the laboratory instrument PROGRA2 (e. g. Hadamcik et al., 2007; Francis et al., 2011). Long-duration balloons flights from weeks to months with daily vertical excursions and carrying a poly-instrumented gondola could be also useful to better evaluate the temporal and spatial variability of NSPS in the stratosphere. Aerosols counter and mass spectrometer can be part of the gondola, but also a possible future instrument that can derive the isotopic composition of the solid 
material to better distinguish between the various sources, as proposed by Kalashnikova et al., 2016; Beresnev and Vasiljeva, 2018 for carbonaceous particles.

Remote-sensing measurements from future satellite platforms, like the EarthCARE spaceborne lidar (Illingworth et al., 2015), coupled with balloon-borne measurements, could help to better identify the various natures of stratospheric aerosols and their variability. Finally, a new in-situ counting instrument along the Earth's orbit could be proposed to better estimate the size and the concentration of incoming material from space.

Such improved knowledge of the stratospheric aerosols and the role of the NSPs will be useful for improving chemistry and climate modeling works, including radiative transfer calculations over the whole atmosphere.

Author contribution: Jean-Baptiste Renard designed the LOAC experiment and processed the data. Gwenaël Berthet and Damien Vignelles participated in the improvement of the instrument and of the data processing, and in the data interpretation. Anny-Chantal Levasseur-Regourd, Sergey Beresnev, Alain Miffre, Patrick Rairoux and Fabrice Jégou participated in the analysis of the origin of the aerosols and of their spatial and temporal variability.

Acknowledgments. The LOAC instruments were funded by the French Labex "Étude des géofluides et des VOLatils-Terre, Atmosphère et Interfaces - Ressources et Environnement" (VOLTAIRE) (ANR-10-LABX-100-01) managed by the University of Orleans. The STAC and LOAC flights were funded by the French Space Agency CNES. We want to thank the CNES balloons launching team at Aire sur l'Adour, the MeteoModem Company for the flight for Ury (France), and Nelson Bègue and the LACy for the flights at Ile de la Réunion. We want to thank Marie-Agnès Courty for information concerning the local production of nanocomposite in the atmosphere, Andrei Vedernikov for fruitful discussion, and finally CNES for its support in the scientific analysis of Rosetta data. Sergey Beresnev want to thank the Ministry of Science and Higher Education of the Russian Federation, the research project \#3.6064.2017/8.9.

The STAC data are available at: https://cds-espri.ipsl.upmc.fr/etherTypo/index.php?id=667\&L=1 The 2013 LOAC data are available at: http://mistrals.sedoo.fr/?editDatsld=1017\&datsld=1017\&project_name=ChArMEx The LOAC data from 2014 are available at: https://cds-espri.ipsl.upmc.fr/etherTypo/index.php?id=1699\&L=1

\section{References}

Adachi, K., Chung, S. H., Friedrich, H., and Buseck, P. R., Fractal parameters of individual soot particles determined using electron tomography: implications for optical properties, J. Geophys. Res., 112, D14202, doi:10.1029/2006JD008296, 2007. 
Ansmann, A., Baars, H., Chudnovsky, A., Mattis, I., Veselovskii, I., Haarig, M., Seifert, P., Engelmann, R., and Wandinger, U., Extreme levels of Canadian wildfire smoke in the stratosphere over central Europe on 21-22 August 2017, Atmos. Chem. Phys., 18, 1183111845, 2018.

Antonsen, T., Havnes, O., and Mann, I., Estimates of the size distribution of Meteoric smoke particles from rocket-borne impact probes, J. Geophys. Res., 122, 12,353-12,365. https://doi.org/10.1002/2017JD027220, 2017.

Bardeen, C. G., Toon, O. B., Jensen, E. J., Marsh, D. R., and Harvey, V. L., Numerical simulation of the three-dimensional distribution of meteoric dust in the mesosphere and upper stratosphere, J. Geophys. Res., 113, D17202, doi:10.1029/2007JD009515, 2008.

Bardyn, A., Baklouti, D., Cottin, H., Fray, N., Briois, C., Paquette, J., Stenzel, O., Engrand, C., Fischer, H., Hornung, Isnard, R., Langevin, Y., Lehto, H., Le Roy, L., Ligier, N., Merouane, S., Modica, P., Orthous-Daunay, F.-R., Rynö, J., Schulz, R., Silén, J., Thirkell, L., Varmuza, K., Zaprudin, B., Kissel, J., and Hilchenbach, M., Carbon-rich dust in comet 67P/ChuryumovGerasimenko measured by COSIMA/Rosetta, MNRAS, 469, S712-S722, doi.org/10.1093/mnras/stx2640, 2017.

Baumgardner, D., Kok, G., and Raga, G., Warming of the Arctic lower stratosphere by light absorbing particles, Geophys. Res. Lett., 31, L06117, doi:10.129/2003GL0118883, 2004.

Bègue, N., Vignelles, D., Berthet, G., Portafaix, T., Payen, G., Jégou, F., Benchérif, H., Jumelet, J., Vernier, J.-P., Lurton, T., Renard, J.-B., Clarisse, L., Duverger, V., F. Posny, F., Metzger, J.M., and Godin-Beekmann, S., Long-range transport of stratospheric aerosols in the Southern hemisphere following the 2015 Calbuco eruption, Atmos. Chem. Phys, 17, 15019-15036, 2017.

Beresnev S., Vasiljeva, M., and Suetin, D. Predictions and detection of the "accommodation" forces on Janus particles subjected to directed radiation in a rarefied gas, Vacuum, 86, doi:10.1016/j.vacuum.2012.01.022, 1663-1668, 2012.

Beresnev, S. A., Vasil'eva, M. S., Gryazin, V. I., and Kochneva, L., B., Photophoresis of fractallike soot aggregates: microphysical model, comparison with experiment, and possible atmospheric manifestations, atmospheric and oceanic optics, 30(6), 527-532, doi: 10.1134/S1024856017060045, 2017.

Beresnev, S. A., and Vasiljeva, M. S., Black carbon aerosol in stratosphere, Proc. SPIE 10833, 24th International Symposium on Atmospheric and Ocean Optics: Atmospheric Physics, 108339D, doi:10.1117/12.2503881, 2018.

Berthet, G., Renard, J.-B., Brogniez, C., Robert, C., Chartier, M., and Pirre, M., Optical and physical properties of stratospheric aerosols from balloon measurements in the visible and near-infrared domains: 1 . Analysis of aerosol extinction spectra from the AMON and SALOMON balloonborne spectrometers, Applied Optics, Vol 41, N³6, 7522-7539, 2002. 
1177

1178

1179

1180

1181

1182

1183

1184

1185

1186

1187

1188

1189

1190

1191

1192

1193

1194

1195

1196

1197

1198

1199

1200

1201

1202

1203

1204

1205

1206

1207

1208

1209

1210
Berthet, G., Renard, J.-B., Catoire, V., Chartier, M., Robert, C., Huret, N.,Coquelet, F., and Bourgeois, Q., Remote sensing measurements in the polar vortex: comparison to in situ observations and implications for the simultaneous retrievals and analysis of the $\mathrm{NO}_{2}$ and OClO species, J. Geophys. Res., Vol.112, D21310, doi:10.1029/2007JD008699, 2007.

Bingen, C., Fussen, D., and Vanhellemont, F., A global climatology of stratospheric aerosol size distribution parameters derived from SAGE II data over the period 1984-2000: 2. Reference data, J. Geophys. Res., 109, D06202, 2004.

Bound, T. C., and Bergstrom, R. W., Light absorption by carbonaceous particles: an investigative review, Aerosol Science and Technology, 40(1), 27-67, doi.org/10.1080/02786820500421521, 2007.

Bourgeois, Q., Ekman, A. M. L., Renard, J.-B., Krejci, R. Devasthale, A., Bender, A.-M., Riipinen, I., Berthet, G., and Tackett, J. L., How much of the global aerosol optical depth is found in the bondry layer and free troposphere, Atmos. Chem. Phys., 18, 7709-7720, https://doi.org/10.5194/acp-18-7709-2018, 2018.

Blake, D. F., and Kato, K., Latitudinal distribution of black carbon soot in the upper troposphere and the lower stratosphere, J. Geophys. Res., 100, 7195-7202, 1995.

Bourassa, A. E., Rieger, L. A., Lloyd, N. D., and Degenstein, D. A., Odin-OSIRIS stratospheric aerosol data product and SAGE III intercomparison, Atmos. Chem. Phys., 12, 605-614, doi:10.5194/acp-12-605-2012, 2012

Brownlee, D. E., Microparticle studies by sampling techniques, Cosmic Dust, J. McDonnell ED., Wiley, 295-336, 1978.

Brownlee, D. E., Cosmic dust: collection and research, Ann. Rev. Earth Planet. Sci., 13, 147173, 1985.

Carrillo-Sánchez, J. D., Nesvorný, D., Pokorný, P., Janches, D. and Plane, J. M. C., Sources of cosmic dust in the Earth's atmosphere, Geophys. Res. Lett.,43, 11,979-11,986, doi:10.1002/ 2016GL071697, 2016.

Chane-Ming, F., Vignelles, D., Jegou, F., Berthet, G., Renard, J.-B., Gheusi, F., and Kuleshov, Y., Gravity-wave effects on tracer gases and stratospheric aerosol concentrations during the 2013 ChArMEx campaign, Atmos. Chem. Phys., 16, 8023-8042, doi:10.519/acp-16-80232016, 2016.

Ciucci, A., Palumbo, P., Brunetto, R., Della Corte, V., De Angelis, S., Rotundi, A., Rietmeijer, F.J.M., Zona, E., Colangeli, L., Esposito, F., Mazzotta Epifani, E., Mennella, V., Inarta, S., Peterzen, S., Masi, S., and Ibba, R., DUSTER (Dust in the Upper Stratosphere Tracking Experiment and Retrieval) preliminary analysis, Memorie della Società Astronomica Italiana, 75, 282-287, 2008. 
Coulson, S. G., Wallus, M. K., and Wickramasinghe, N. C., On the dynamics of volatile meteorites, Monthly Notices of the Royal Astronomical Society, 445, 3669-3673, 2014.

Courty, M.-A., and Martinez, J.-M., Terrestrial carbonaceous debris tracing atmospheric hypervelocity-shock aeroplasma processes, Procedia Engineering, 103, 81-88, 2015.

Curtius, J., Weigel, R., Vossing, H.-J., Wernli, H., Werner, A., Volk, C.M, Konopka, P., Krebsbach, M. , Schiller, C. , Roiger, A., Schlager, H., Dreiling, V., and Borrmann, S., Observations of meteoric material and implications for aerosol nucleation in the winter Arctic lower stratosphere derived from in situ particle measurements, Atmos. Chem. Phys., 5, 3053-3069, 2005.

Cziczo, D. J., Murphy, D. M., Thomson, D. S., and Ross, M. N., Composition of individual particles in the wakes of an Athena II rocket and the space shuttle, Geophys. Res. Lett., 29, 21, 2037, doi:10.1029/2002GL015991, 2002.

Damoah, R., Spichtinger, N., Servranckx, R., Fromm, M., Eloranta, E. W., Razenkov, I. A., James, P., Shulski, M., Forster, C., and Stohl, A., A case study of pyro-convection using transport model and remote sensing data, Atmos. Chem. Phys., 6, 173-185, 2006.

Dartois, E., Engrand, C., Duprat, J., Godard, M., Charon, E., Delauche, L., Sandt, C., and Borondics, F., Dome C ultracarbonaceous Antarctic micrometeorites. Infrared and raman fingerprints, Astron. Astrophys., 609, A65, 2018.

Della Corte, V., Rietmeijer, F.J.M., Rotundi, A., Ferrari, M., and Palumbo, P., Meteoric CaO and carbon smoke particles collected in the upper stratosphere from an unanticipated source, Tellus B, 65, 20174, 2013.

de Laat, A.T.J., Stein Zweers, D.C., Boers, R., and Tuinder, O.N.E., A solar escalator: Observational evidence of the self-lifting of smoke and aerosols by absorption of solar radiation in the February 2009 Australian Black Saturday plume, J. Geophys. Res., 117, D04204, doi:10.1029/2011JD017016, 2012.

Dermott, S.F., Nicholson, P.D., Burns, J.A., and Houck, J.R., On the origin of the IRAS solar system dust bands, Nature, 312, 505-509, 1984.

Deshler, T., Hervig, M. E., Hofmann, D. J., Rosen, J. M., and Liley, J. B., Thirty years of in situ stratospheric aerosol size distribution measurements from Laramie, Wyoming $\left(41^{\circ} \mathrm{N}\right)$ using balloon-borne instruments J. Geophys. Res., 108, D5 4167, doi:10.1029/2002JD002514, 2003.

Deshler, T., Richard Anderson-Sprecher, R., Jäger, H., Barnes, J., Hofmann, D. J., Clemesha, B., Simonich, D., Osborn, M., Grainger, R. G., and Godin-Beekmann, S., Trends in the nonvolcanic component of stratospheric aerosol over the period 1971-2004, 111, D01201, 10.1029/2005JD006089, 2006. 
Dobrica, E., Engrand, C., Duprat, J., and Gounelle, M., A statistical overview of concordia antarctic micrometeorites. Meteorit. Planet. Sci. Suppl., 45, A46, 2010.

Ebert, M., Weigel, R., Kandel, K., Günther, G., Molleker, S., Groob, J.-U. Vogel, B., Weinbruch, S., and Borrmann, S., Chemical analysis of refractory stratospheric aerosol particles collected within the arctic vortex and inside polar stratospheric clouds, Atmos. Chem. Phys. 16, 84058421, 2016.

Engrand, C., and Maurette, M., Carbonaceous micrometeorites from Antarctica. Meteoritics \& Planetary Science 33:565-580, 1998.

Fadnavis, Suvarna, Gayatry Kalita, K. Ravi Kumar, Blaž Gasparini, and Jui-Lin Frank Li, Potential impact of carbonaceous aerosol on the upper troposphere and lower stratosphere (UTLS) and precipitation during Asian summer monsoon in a global model simulation, Atmos. Chem. Phys., 17, 11637-11654, 2017.

Flynn, G.J., Wirick, S., and Keller, L.P., Organic grain coatings in primitive interplanetary dust particles, Earth Planets Space, 65, 13, 2013.

Fortov, V. E., Sultanov, V. G., and Shutov, A. V., Chelyabinsk superbolide explosion in the Earth's atmosphere: A common phenomenon or unique coincidence?

Francis, M., Renard, J.-B., Hadamcik, E., Couté, B., Gaubicher, B., and Jeannot, M., New studies on scattering properties of different kinds of soot, JQSRT, 112, 1766-1775, 2011.

Fromm, M., and R. Servranckx, Transport of forest fire smoke above the tropopause by supercell convection, Geophys. Res. Lett., 30(10), 1542, doi:10.1029/2002/GL016820, 2003.

Fromm, M., Bevilacqua, R., Servranckx, R., Rosen, J., Thayer, J.P., Herman, J., and Larko, D., Pyro-cumulonimbus injection of smoke to the stratosphere: Observations and impact of a super blowup in northwestern Canada on 3-4 August 1998, J. Geophys. Res., 110, D08205, doi:10.1029/2004JD005350, 2005.

Fromm, M., Tupper, A., Rosenfeld, D., Servranckx, R., and McRae, R., Violent pyroconvective storm devastates Australia's capital and pollutes the stratosphere, Geophys. Res. Lett., 33, L05815, doi:10.1029/2005GL025161, 2006.

Füllekrug, M., Diver, D., Pinçon, J.-L., Phelps, A. D. R., Bourdon, A., Helling, C., Blanc, E., Honary, F., Harrison, R. G., Sauvaud, J.-A., Renard, J.-B., Lester, M., Rycroft, M., Kosch, M., Horne, R. B., Soula, S., and Gaffet, S., Energetic Charged Particles Above Thunderclouds, Surveys in Geophysics, doi:10.1007/s10712-012-9205-z, 2013.

Gao, R. S., Telg, H., McLaughlin, R. J., Ciciora, S. J., Watts, L. A., Richardson, M. S., Schwarz, J. P., Perring, A. E., Thornberry, T. D., Rollins, A. W., Markovic, M. Z., Bates, T. S., Johnson, J. E., and Fahey, D. W., A light-weight, high-sensitivity particle spectrometer for PM2.5 aerosol measurements, Aerosol Science and Technology, 50:1, 88-99, DOI: 10.1080/02786826.2015.1131809, 2016. 
Gerding, M., Baumgarten, G., Blum, U., Thayer, J. P., Fricke, K.-H., Neuber, R., and Fiedler, J., Observation of an unusual mid-stratospheric aerosol layer in the Arctic: possible sources and implication for polar vortex dynamics (2003), Ann. Geophys., 21, 1057-1069, 2003.

1309

1310

1311

1312

1313

1314

1315

1316

1317

1318

1319

1320

1321

1322

1323

1324

1325

1326

1327

1328

1329

1330

1331

1332

1333

1334

1335

1336

1337

1338

1339

1340

1341

1342

1343

1344
Gorkavyi, N., Rault, D. F., Newman, P. A., da Silva, A. M., and Dudorov, A. E., New stratospheric dust belt due to the Chelyabinsk bolide, Geophys. Res. Lett., 40, 4728-4733, doi:10.1002/grl.50788, 2013.

Govardhan, G., Krishnakumari Satheesh, S., Nanjundiah, R., Krishna Moorthy, K., and Suresh Babu, S., Possible climatic implications of high-altitude black carbon emissions, Atmos. Chem. Phys., 17, 9623-9644, 2017.

Gryazin, V.I., and Beresnev, S.A., Influence of vertical wind on stratospheric aerosol transport, Meteorol. Atmos. Phys., 110, 151-162, doi: 10.1007/s00703-010-0114-8, 2011.

Günther, A., Höpfner, M., Sinnhuber, B.-M., Griessbach, S., Deshler, T., von Clarmann, T., and Stiller, G., MIPAS observations of volcanic sulfate aerosol and sulfur dioxide in the stratosphere, Atmos. Chem. Phys., 18, 1217-1239, 2018.

Hadamcik, E., Renard, J.-B., Lasue, J., Levasseur-Regourd, A.C., Blum, J., and Shraepler, R., Light scattering by low density agglomerates of micron-sized grains with the PROGRA2 experiment, JQSRT, 106, 74-89, doi.org/10.1016/j.jqsrt.2007.01.008, 2007.

Haarig, M., Ansmann, A., Baars, H., Jimenez, C., Veselovskii, I., Engelmann, R., and Althausen, D., Depolarization and lidar ratios at 355, 532, and $1064 \mathrm{~nm}$ and microphysical properties of aged tropospheric and stratospheric Canadian wildfire smoke, Atmos. Chem. Phys., 18, 11847-11861, 2018, doi.org/10.5194/acp-18-11847-2018

Hamdan, A., Kabbara, H., Courty, M.-A., Cha, M. S., Martinez, J.-M., and Belmonte, T., Synthesis of carbon-metal multi strand nanocomposites by discharges in heptane between two metallic electrodes, Plasma Chem. Plasma Preocess, 37, 1069-1090, 2017.

Hendricks, J., Kärcher, B., Döpelheuer, A., Feichter, J., Lohmann, U., and Baumgardner, D., Simulating the global atmospheric black carbon cycle: A revisit to the contribution of aircraft emission, Atmos. Chem. Phys., 4, 2521-2541, 2004.

Herique, A., Kofman, W., Beck, P., Bonal, L., Buttarazzi, I., Heggy, E., Lasue, J., LevasseurRegourd, A.C., Quirico, E., and Zine, S., Cosmochemical implications of CONSERT permittivity characterization of 67P/CG, MNRAS, 462, S516-S532, doi.org/10.1093/mnras/stx040, 2017. 

Delanoë, J., Domenech, C., Donovan, D. P., Fukuda, S., Hirakata, M., Hogan, R. J., Huenerbein, A., Kollias, P., Kubota, T., Nakajima, T., Nakajima, T. Y., Nishizawa, T., Ohno, Y., Okamoto, H., Oki, R., Sato, K., Satoh, M., Shephard, M. W., Velázquez-Blázquez, A., Wandinger, U., Wehr, T., and Van Zadelhoff, G.-J., The EarthCARE Satellite: The Next Step Forward in Global Measurements of Clouds, Aerosols, Precipitation, and Radiation, Bull. American Meteo. Soc., 2015, 96 (8), 1311-1332, 2015.

Hunten, D. M., Turco, R. P., and Toon, O. B., Smoke and dust particles of meteoric origin in the mesosphere and stratosphere, J. Atmos. Sci., 37, 1342-1357, 1980.

1355

Ishii, H.A., Bradley, J.P., Dai, Z.R., Chi, M., Kearsley, A.T., Burchell, M.J., Browning, N.D., and Molster, F., Comparison of comet 81P/Wild 2 dust with interplanetary dust from comets, Science, 319, 447, 2008.

1359

Jégou, F., Berthet, G., Brogniez, C., Renard, J.-B., Francois, P., Haywood, J. M., Jones, A., Bourgeois, Q., Lurton, T., Auriol, F., Godin-Beekmann, S., Guimbaud, C., Krysztofiak, G., Gaubicher, B., Chartier, M., Clarisse, L., Clerbaux, C., Balois, J.-Y., Verwaerde, C., and D. Daugeron, Stratospheric aerosols from the Sarychev volcano eruption in the 2009 Arctic summer, Atmos. Chem. Phys., 13, 6533-6552, 2013, doi:10.5194/acp-13-6533-2013, 2013.

1365

1366

Jessberger, E.K., Stephan, T., Rost, D., Arndt, P., Maetz, M., Stadermann, F.J., Brownlee, D.E., Bradley, J.P., and Kurat, G., Properties of interplanetary dust: Information from collected samples, In: Interplanetary Dust (Grün, E., Gustafson, B.A.S, Dermott, S.F., and Fechtig, H., Eds), Springer-Verlag, Berlin, 253-294, 2001.

Jost, H.-J., Drdla, K., Stohl, A., Pfister, L., Loewenstein, M., Lopez, J. P., Hudson, P. K., Murphy, D. M., Cziczo, D. J., Fromm, M., Bui, T. P., Dean-Day, J., Gerbig, C., Mahoney, M. J., Richard, E. C., Spichtinger, N., Vellovic Pittman, J., Weinstock, E., M., Wilson, J., and Xueref, I., In-situ observations of mid-latitude forest fire plumes deep in the stratosphere, Geophys. Res. Lett., 31, doi:10.1029/2003GL019253, 2004.

1376

1377

Kalashnikova, O., Horanyi, M., Thomas, G. E., and Toon, O. B., Meteoric smoke production in the atmosphere, Geophys. Res. Lett., 27(20), 3293-3296, 2000.

1379

1380

Kalashnikova, D.A., Markelova, A.N., Melkov, V.N., and Simonova, G.V., Isotope composition of pyrogenic carbon of various origins, Chem. Sustain. Develop. 24, 467-471, 2016.

1382

1383

Khaykin, Sergey M., Sophie Godin-Beekmann, Philippe Keckhut, Alain Hauchecorne, Julien Jumelet, Jean-Paul Vernier, Adam Bourassa, Doug A. Degenstein, Landon A. Rieger, Christine Bingen, Filip Vanhellemont, Charles Robert, Matthew DeLand, and Pawan K. Bhartia, Variability and evolution of the midlatitude stratospheric aerosol budget from 22 years of ground-based lidar and satellite observations, Atmos. Chem. Phys., 17, 1829-1845, 2017.

Khaykin, S. M., Godin-Beekmann, S., Hauchecorne, A., Pelon, J., Ravetta, F., and Keckhut, P., Stratospheric smoke with unprecedentedly high backscatter observed by lidars above southern France, Geophys. Res. Lett., 1944, 8007, doi:10.1002/2017GL076763, 2018. 
Klekociuk, A., Brown, P. G., Pack, D. W., ReVelle, D. O., Edwards, W. N., Spalding, R. E., Tagliaferri, E., Yoo, B., B., and Zagari, J., Meteoritic dust from the atmospheric disintegration of a large meteoroid, Nature, 436, doi:10.1038/nature03881, 2005.

1396

1397

1398

1399

1400

1401

1402

1403

1404

1405

1406

1407

1408

1409

1410

1411

1412

1413

1414

1415

1416

1417

1418

1419

1420

1421

1422

1423

1424

1425

1426

1427

1428

1429

1430

1431

1432

1433

1434

1435

1436

1437
Kloss, C., Berthet, G., Sellitto, P., Ploeger, F., Bucci, S., Khaykin, S., Jégou, F., Taha, G., Thomason, L., Barret, B., Le Flochmoen, E., von Hobe, M., Bossolasco, A., Begue, N., and Legras, B., Transport of the 2017 Canadian wildfire plume to the tropics and global stratosphere via the Asian monsoon circulation, ACP Discussions, https://doi.org/10.5194/acp-2019-204, 2019.

Koschny, D., Soja, R., Engrand, C., Flynn, G., Lasue, J., Levasseur-Regourd, A. C., Malaspina, D., Nakamura, T., Poppe, A. R., Sterken, V. J., and Trigo-Rodríguez, J. M., Space Science Reviews, 215-34, doi.org/10.1007/s11214-019-0597-7, 2019.

Kremser, S., Thomason, L. W., von Hobe, M., Hermann, M., Deshler, T., Timmreck, C., Toohey, M., Stenke, A., Schwarz, J. P., Weigel, R., Fueglistaler, S., Prata, F. J., Vernier, J.-P., Schlager, H., Barnes, J. E., Antuña-Marrero, J.-C., Fairlie, D., Palm, M., Mahieu, E., Notholt, J., Rex, M., Bingen, C., Vanhellemont, F., Bourassa, A., Plane, J. M. C., Klocke, D., Carn, S. A., Clarisse, L., Trickl, T., Neely, R., James, A. D., Rieger, L., Wilson, J. C., and Meland, B., Stratospheric aerosol - Observations, processes, and impact on climate, Rev. Geophys., 54, 278-335, 2016.

Langevin, Y., Hilchenbach, M., Ligier, N., Merouane, S., Hornung, K., Engrand, C., Schulz, R., Kissel, J., Rynö, J., and Eng, P., Typology of dust particles collected by the COSIMA mass spectrometer in the inner coma of 67P/Churyumov-Gerasimenko, Icarus, 271, 76-97, 2016.

Lasue, J., Levasseur-Regourd, A.C., Fray, N., and Cottin, H. Inferring the interplanetary dust properties from remote observations and simulations, Astronomy \& Astrophysics, 473, 641649, doi: 10.1051/0004-6361:20077623, 2007.

Levasseur, A.C., and Blamont, J.E., Satellite observations of intensity variations of the zodiacal light, Nature, 246, 5427, 26-28, 1973.

Levasseur-Regourd A.C., Mann, I., Dumont, R., and Hanner, M.S., Optical and thermal properties of interplanetary dust. In: Interplanetary Dust (Grün, E., Gustafson, B.A.S, Dermott, S.F., and Fechtig, H., Eds), Springer-Verlag, Berlin, 57-94, 2001.

Levasseur-Regourd, A.C., and Lasue, J., Inferring sources in the interplanetary dust cloud, from observations and simulations of zodiacal light and thermal emission, In Meteoroids: the smallest solar system bodies, NASA/CP-2011-216469, 66-75, 2011.

Levasseur-Regourd, A.C., Agarwal, J., Cottin, H., Engrand, C., Flynn, G., Fulle, M., Gombosi, T., Langevin, Y., Lasue, J., Mannel, T., Merouane, S., Poch, O., Thomas, N., and Westphal, A., Cometary dust, Space Sci. Rev., 214, 64-119, doi.org/10.1007/s11214-018-0496-3, 2018. 
Love, S., and Brownlee, D., A direct measurement of the terrestrial mass accretion rate of cosmic dust, Science 262, 54-58, 1993.

Lurton, T., Renard, J.-B., Vignelles, D., Jeannot, M., Akiki, R., Mineau, J.-L., and Tonnelier, T., Light scattering at small angles by atmospheric irregular particles: modelling and laboratory measurements, Atmospheric Measurement Techniques, Atmos. Meas. Tech., 7, 931-939, 2014.

Mannel, T., Bentley, M.S., Schmied, R., Jeszenszky, H., Levasseur-Regourd, A.C., Romstedt, J., and Torkar, K., Fractal cometary dust: a window into the early Solar System, MNRAS, 462, S304-S311, doi.org/10.1093/mnras/stw2898, 2016.

Mannel, T., Bentley, M. S., Boakes, P., Jeszenszky, H., Ehrenfreund, P., Engrand, C., Koeberl, C., Levasseur-Regourd, A. C., Romstedt, J., Schmied R., Torkar K., and Weber, I. Astronomy and Astrophysics, 2019, 630, A26 (14 p.), doi.org/10.1051/00046361/201834851, 2019.

Mateshvili, N., Mateshvili, G., Mateshvili, I., Gheondjian, L., and Avsajanishvili, Vertical distribution of dust particles in the Earth's atmosphere during the 1998 Leonids, Meteoritics B Planetary Science 34, 969-913, 1999.

Mandeville, J.-C., Study of cosmic dust particles on board LDEF and MIR space station, Origin and Evolution of interplanetary dust, A.C. Levasseur-Regourd and H. Hasegawa eds., Kluwer Academic Publishers, 11-14, 1991.

Merouane, S., Zaprudin, B., Stenzel, O., Langevin, Y., Altobelli, N., Della Corte, V., Fischer, H., Fulle, M., Hornung, K., Silén, J., Ligier, N., Rotundi, A., Ryno, J., Schulz, R., Hilchenbach, M., Kissel, J., and the COSIMA Team, Dust particle flux and size distribution in the coma of 67P/Churyumov-Gerasimenko measured in situ by the COSIMA instrument on board Rosetta, A\&A 596, A87, 2016.

Mishchenko, M.I., Hovenier, J. W., and Mackowski, D. W., Single scattering by a small volume element, J. Opt. Soc. Amer. A, 21, 71-87, doi:10.1364/JOSAA.21.000071, 2004.

Miffre, A., Anselmo, C., Geffroy, S., Fréjafon, E., and Rairoux, P., Lidar remote sensing of laser-induced incandescence on light absorbing particles in the atmosphere, Optics Express, 23 (3), 2347-2360, 2015.

Murphy, D. M., Thomson, D. S., and Mahoney, M. J., In situ measurements of organics, meteoritic material, mercury, and other elements in aerosols at 5 to 19 kilometers, Science, 282, 1664-1669, 1998.

Murphy, D. M., Cziczo, D. J., Hudson, P. K., and Thomson, D. S., Carbonaceous material in aerosol particles in the lower stratosphere and tropopause region, J. Geophys. Res., 112, D04203, doi:10.1029/2006JD007297, 2007. 
1510

Murphy, D. M., Froyd, K. D., Schwarz, J. P., and Wilson, J. C., observation of the chemical composition of stratospheric aerosol particles, Q. J. R. Meteorol. Soc., 140, 1269-1278, 2014.

Nakamura, T., Noguchi, T., Ozono, Y., Osawa, T., and Nagao, K., Mineralogy of ultracarbonaceous large micrometeorites, Meteorit. Planet. Sci., 40 (Suppl), 5046, 2005.

Neely, R. R., J. M. English, O. B. Toon, S. Solomon, M. Mills, and J. P. Thayer, Implications of extinction due to meteoritic smoke in the upper stratosphere, Geophys. Res. Lett. 38, L24808, doi:10.1029/2011GL049865, 2011.

Nesvorný, D., Jenniskens, P., Levison, H.F., Bottke, W.F., Vokrouhlicky, D., and Gounelle, M., Cometary origin of the zodiacal cloud and carbonaceous micrometeorites: Implications for hot debris disks, The Astrophysical Journal, 713, 816-836, 2010.

Newman, P.A., Wilson, J.C., Ross, M.N., Brock, C.A., Sheridan, P.J., Schoeberl, M.R., Lait, L.R., Bui, T.P., Loewenstein, M., and Podolske, J.R., Chance encounter with a stratospheric kerosene rocket plume from Russia over California. Geophys. Res. Lett. 28 (6), 959-962, 2001.

Niemeier, U., Timmreck, C., Graf, H.-F., Kinne, S., Rast, S., and Self, S., Initial fate of fine ash and sulfur from large volcanic eruption, Atmos. Chem. Phys., 9, 9043-9057, 2009

Padma Kumari, B., Trigo-Rodriguez, J. M., Londhe, A. L., Jadhav, D. B., and Trimbake, H. K., Optical observations of meteoric dust in the middle stratosphere during Leonid activity in recent years 2001-2003 over India, Geophys. Res. Lett., 32, L16807, doi:10.1029/2005GL023434, 2005.

Padma Kumari, B., Kulkarni, H., Jadhav, D. B., Londhe, A. L., and Trimbake, H. K., Exploring Atmospheric aerosols by twilight photometry, Journal of Atmospheric and Oceanic Technology, 25, 1600-1607, 2008.

Pereira, J., Massereau-Guilbaud, V., Géraud-Grenier, I., and Plain, A., CH and CN radical contribution in the particle formation generated in a radio-frequency $\mathrm{CH} 4 / \mathrm{N} 2$ plasma, Plasma Process. Polym., 2, 633-640 DOI: 10.1002/ppap.200500014, 2005.

Peterson D. A., Campbell, J. R., Hyer, E. J., Fromm, M. D., Kablick III, G. P., Cossuth, J. H., and DeLand, M. T., Wildfire-driven thunderstorms cause a volcano-like stratospheric injection of smoke. npj Climate and Atmospheric Science 1:2397-3722, 2018.

Plane, J. M. C., Atmospheric chemistry of meteoric metals, Chem. Rev., 103, 4963-4984, 2003.

Plane, J. M. C., Cosmic dust in the earth's atmosphere, Chem. Soc. Rev., 41, 6507-6518, 2012. 

and Listowsky, C., Impacts of cosmic dust on planetary atmospheres and surfaces, Space Sci. Rev., 214:23, https://doi.org/10.1007/s11214-017-0458-1, 2018.

1533

1534

1535

1536

1537

1538

1539

1540

1541

1542

1543

1544

1545

1546

1547

1548

1549

1550

1551

1552

1553

1554

1555

1556

1557

1558

1559

1560

1561

1562

1563

1564

1565

1566

1567

1568

1569

1570

1571

1572

1573

1574

1575
Pueschel, R. F., Black, D. F., Snetsinger, K. G., Hansen, A. D. A., Verma, S., and Kato, K., Black carbon (soot) in the lower stratosphere and upper troposphere, Geophys. Res. Lett., 19(16), 1659-1662, 1992.

Pueschel, R.F., Boering, K.A., Verma, S., Howard, S.D., Ferry, G.V., Goodman, J., Allen, D.A., and Hamil, P., Soot aerosol in the lower stratosphere: Pole-to-pole variability and contributions by aircraft, J. Geophys. Res., 102, D11, 13,113-13,118, 1997.

Pueschel, R. F., Verma, S., Rohatschek, H., Ferry, G. V., Boiadjieva, N., Howard, S. D., and Strawa, A. W., Vertical transport of anthropogenic soot aerosol into the middle atmosphere, J. Geophys. Res., 105, 3727-3736, 2000.

Rapp, M., Strellnikova, I., and Gumbel, J., Meteoric smoke particles: Evidence from rocket and radar techniques, Adv. Space Res., 40., 809-817, 2007.

Reach, W.T., Kelley, M.S., and Sykes, M.V., A survey of debris trails from short-period comets. Icarus, 191, 298-322, 2007.

Renard, J.-B., Berthet, G., Robert, C., Chartier, M., Pirre, M., Brogniez, C., Herman, M., Verwaerde, C., Balois, J.-Y., Ovarlez, J., Ovarlez, H., Crespin, J., and Deshler, T., Optical and physical properties of stratospheric aerosols from balloon measurements in the visible and near-infrared domains : 2. Comparison of extinction, reflectance, polarization and counting measurements, Applied Optics, Vol 41, №36, 7540-7549, 2002.

Renard, J.-B., Ovarlez, J., Berthet, G., Fussen, D., Vanhellemont, F., Brogniez, C., Hadamcik, E., Chartier, M., and Ovarlez, H., Optical and physical properties of stratospheric aerosols from balloon measurements in the visible and near-infrared domains. III. Presence of aerosols in the middle stratosphere, Applied Optics, vol. 44, $\mathrm{N}^{\circ} 19,4086-4095,2005$.

Renard, J.-B., Brogniez, C., Berthet, G., Bourgeois, Q., Gaubicher, B., Chartier, M., Balois, J.-Y. Verwaerde, C., Auriol, F., Francois, P., Daugeron, D., and Engrand, C., Vertical distribution of the different types of aerosols in the stratosphere, Detection of solid particles and analysis of their spatial variability, J. Geophys. Res., 113, D21303, doi:10.1029/2008JD010150, 2008.

Renard, J.-B., Berthet, G., Salazar, V., Catoire, V., Tagger, M., Gaubicher, B., and Robert, C., In situ detection of aerosol layers in the middle stratosphere, Geophys. Res. Lett., 37, L20803, doi:10.1029/2010GL044307, 2010.

Renard, J.-B., Tripathi, S. N., Michael, M., Rawal, A., Berthet, G., Fullekrug, M., Harrison, R. G., Robert, C., Tagger, M., and Gaubicher, B., In situ detection of electrified aerosols in the upper troposphere and stratosphere, Atmos. Chem. Phys., 13, 11187-11194, 2013, doi:10.5194/acp-13-11187-2013. 
Renard, J.-B., Dulac, F., Berthet, G., Lurton, T., Vignelles, D., Jégou, F., Tonnelier, T., Jeannot, M., Couté, B., Akiki, R., Verdier, N., Mallet, M., Gensdarmes, F., Charpentier, P., Mesmin, S., Duverger, V., Dupont, J.-C., Elias, T., Crenn, V., Sciare, J., Zieger, P., Salter, M., Roberts, T., Giacomoni, J., Gobbi, M., Hamonou, E., Olafsson, H, Dagsson-Waldhauserova, P., CamyPeyret, C., Mazel, C., Décamps, T., Piringer, M., Surcin, J., and Daugeron, D.: LOAC, a light aerosols counter for ground-based and balloon measurements of the size distribution and of the main nature of atmospheric particles, 1 . Principle of measurements and instrument evaluation, Atmos. Meas. Tech., 9, 1721-1742, doi:10.5194/amt-9-1721-2016, 2016a.

1585

Renard, J.-B., Dulac, F., Berthet, G., Lurton, T., Vignelles, D., Jégou, F., Tonnelier, T., Jeannot, M., Couté, B., Akiki, R., Verdier, N., Mallet, M., Gensdarmes, F., Charpentier, P., Mesmin, S., Duverger, V., Dupont, J.-C., Elias, T., Crenn, V., Sciare, J., Zieger, P., Salter, M., Roberts, T., Giacomoni, J., Gobbi, M., Hamonou, E., Olafsson, H, Dagsson-Waldhauserova, P., CamyPeyret, C., Mazel, C., Décamps, T., Piringer, M., Surcin, J., and Daugeron, D.: LOAC, a light aerosols counter for ground-based and balloon measurements of the size distribution and of the main nature of atmospheric particles, 2. First results from balloon and unmanned aerial vehicle flights, Atmos. Meas. Tech., 9, 3673-3686, doi:10.5194/amt-9-3673-2016, $2016 \mathrm{~b}$.

1593

1594

Renard, J.-B., Dulac, F., Durand, P., Bourgeois, Q., Denjean, C., Vignelles, D., Couté, B., Jeannot, M., Verdier, N., and Mallet, M., In situ measurements of desert dust particles above the western Mediterranean Sea with the balloon-borne Light Optical Aerosol Counter/sizer (LOAC) during the ChArMEx campaign of summer 2013, Atmos. Chem. Phys, 18, 3677-3699, http://doi.org/10.5194/acp-18-3677-2018, 2018.

1600

Rieger, L. A., Bourassa, A. E., and Degenstein, D. A., Odin-OSITIS detection of the Chelyabinsk meteor, Atmos. Meas. Tech., 7, 777-780, doi:10.5194/amt7-777-2014, 2014.

1602

1603

1604

1605

Rietmeijer, F.J.M., Interplanetary dust particles, Reviews in mineralogy, 36, 1-96, 1998.

Rohatschek, H., Levitation of stratospheric and mesospheric aerosols by gravitophotophoresis, J. Aerosol Sci., 27, 467-475, 1996.

1607

Ross, M. N., Whitefield, P. D., Hagen, D. E., and Hopkins, A. R., In situ measurement of the aerosol size distribution in stratospheric solid rocket motor exhaust plumes. Geophys. Res. Lett. 26(7), 819-822, 1999.

1611

1612

Rowan-Robinson, M., and May, B., An improved model for the infrared emission from the zodiacal dust cloud: cometary, asteroidal and interstellar dust, MNRAS, 429, 2894-2902, doi.org/10.1093/mnras/sts471, 2013.

1615

1616

Russell, P. B., Livingston, J. M., Pueschel, R. F., Bauman, J. J., Pollack, J. B., Brooks, S. L., Hamill, P., Thomason, L. W., Stowe, L. L., Deshler, T., Dutton, E. G., and Bergstrom, R. W., Global to microscale evolution of the Pinatubo volcanic aerosol derived from diverse measurements and analyses J. Geophys. Res., 101, 18745-18763, 1996.

Salazar, V., Renard, J.-B., Hauchecorne, A., Bekki, S., and Berthet, G., A new climatology of aerosols in the middle and upper stratosphere by alternative analysis of GOMOS 
observations during 2002-2006, International Journal of Remote Sensing, Volume 34, Issue 14, 4986-5029, doi: 10.1080/01431161.2013.786196, 2013.

Sandford, S. A., Engrand, C., and Rotundi, A., Organic Matter in Cosmic Dust, Elements, 12, 185-189, 2016.

Schwarz, J. P., Gao, R. S., Fahey, D. W., Thomson, D. S., Watts, L. A., Wilson, J. C., Reeves, J. M., Darbeheshti, M., Baumgardner, D. G., Kok, G. L., Chung, S. H., Schulz, M., Hendricks, J., Lauer, A., Kärcher, B., Slowik, J. G., Rosenlof, K. H., Thompson, T. L., Langford, A. O., Loewenstein, M., and Aikin, K. C., Single-particle measurements of mid-latitude black carbon and light-scattering aerosols from the boundary layer to the lower stratosphere, J. Geophys. Res., 111, D16207, doi:10.1029/2006JD007076, 2006.

Schütze, K., Wilson, J.C., Weinbruch, S., Benker, N., Ebert, M., Günther, G., Weigel, R., and Borrmann, S., Sub-micrometer refractory carbonaceous particles in the polar stratosphere, Atmos. Chem. Phys. 17, 12475-12493, 2017.

Scott J. D., and Chittenden II, D. M., Chemical composition of particles of $d<0.20 \mathrm{mu}$ in the lower stratospheric aerosol, Spring 1993, Journal of the Arkansas Academy of Science, 56 23, 2002.

Sheng, J.-X., Weisenstein, D. K., Luo, B.-P., Rozanov, E., Stenke, A., Anet, J., Bingemer, H., and Peter, T., Global atmospheric sulfur budget under volcanically quiescent conditions: Aerosolchemistry-climate model predictions and validation, J. Geophys. Res. Atmos., 120, 256-276, doi:10.1002/2014JD021985, 2015.

Siebert, J., Timmis, C., Vaughan, G., and Fricke, K.H., A strange cloud in the Arctic summer stratosphere 1998 above Esrange (68N), Sweden, Ann. Geophysicae 18, 505-509, 2000.

Solomon, S, Daniel, J. S., Nelly, R. R., Vernier, J.-P., Dutton, E. G., and Thomason, L. W., The persistently variable "background" stratospheric aerosol layer and global climate change, Science, 333(6044), 866-870, 2011.

Stein, B., Del Guasta, M., Kolenda, J., Morandi, M., Rairoux, P., Stefanutti, L., Wolf, J. P., and Wöste, L., Stratospheric aerosol size distributions from multispectral lidar measurements at Sodankylä during EASOE, Geophys. Res. Lett., 21 (13), 1311-1314, 1994.

Strawa, A. W., Drdla, K., Ferry, G. V., Verma, S., Pueschel, R. F., Yasuda, M., Salawitch, R. J., Gao, R. S., Howard, S. D., Bui, P. T., Loewenstein, M., Elkins, J. W., Perkins, K. K., and Cohen, R., Carbonaceous aerosol (soot) measured in the lower stratosphere during POLARIS and its role in stratospheric photochemistry, J. Geophys. Res., 104, 26,753-26,766, 1999.

Sykes, M.V., Hunten, D.M., and Low, F.J., Preliminary analysis of cometary dust trails, Adv. Space Res., 6, 67-78, 1986. 
Testa Jr., J. P., Stephens, J. R., Berg, W. W., Cahill, T. A., Onaka, T., Nakada, Y., Arnold, J. R., Fong, N., and Sperry P. D., Collection of microparticles at high balloon altitudes in the stratosphere, Earth and Planetary Science Letters, 98, (3-4), 287-302, 1990.

Thomas K. L., Blanford, G. E., Keller, L. P., Klöck, W., and McKay, D., Carbon abundance and silicate mineralogy of anhydrous interplanetary dust particles, Geochim. Cosmochim. Acta, 57, 1551-1566, 1993.

Thomason, L. W., Ernest, N., Millán, L., Rieger, L., Bourassa, A., Vernier, J.-P., Manney, G., Luo, B., Arfeuille, F., and Peter, T., A global space-based stratospheric aerosol climatology 1979-2016, Earth Syst. Sci. Data, 10, 469-492, 2018 https://doi.org/10.5194/essd-10-4692018, 2018.

Vanhellemont, F., Fussen, D., Mateshvili, N., Tétard, C., Bingen, C., Dekemper, E., Loodts, N., Kyrölä, E., Sofieva, V., Tamminen, J., Hauchecorne, A., Bertaux, J.-L., Dalaudier, F., Blanot, L., Fanton d'Andon, O., Barrot, G., Guirlet, M., Fehr, T., and L. Saavedra, Optical extinction by upper tropospheric/ stratospheric aerosols and clouds: GOMOS observations for the period 2002-2008, Atmos. Chem. Phys., 10, 7997-8009www.atmos-chem-phys.net/10/7997/2010/ doi:10.5194/acp-10-7997-2010, 2010.

Vernier, J. P., Pommereau, J.-P., Garnier, A., Pelon, J., Larsen, N., Nielsen, J., Christensen, T., Cairo, F., Thomason, L. W., Leblanc, T., and McDermid, I. S., Tropical stratospheric aerosol layer from CALIPSO lidar observations, J. Geophys. Res., 114, D00H10, doi:10.1029/2009JD011946, 2009.

Vernier, J.-P., Thomason, L. W., Pommereau, J.-P., Bourassa, A., Pelon, J., Garnier, A., Hauchecorne, A., Blanot, L., Trepte, C., Degenstein, D., and Vargas, F., Major influence of tropical volcanic eruptions on the stratospheric aerosol layer during the last decade, Geophys. Res. Lett., 38, L12807, doi:10.1029/2011GL047563, 2011.

Vernier, J. P., Fairlie, T. D., Deshler, T., Natarajan, M., Knepp, T., Foster, K., Wienhold, F. G., Bedka, K. M., Thomason, L. W., and Trepte, C., In situ and space observations of the Kelud volcanic plume: the persistence of ash in the lower stratosphere, J. Geophys. Res., Atmos., 121, 11,104-11,118, doi:10.1002/2016JD025344, 2016.

Vernier, J.-P., Fairlie, T. D., Deshler, T., Venkat Ratnam, M., Gadhavi, H., Kumar, B. S. Natarajan, M., Pandit, A. K., Akhil Raj, S. T., Hemanth Kumar, A., Jayaraman, A., Singh, A. K., Rastogi, N., Sinha, P. R., Kumar, S., TiwariBanaras, S., Wegner, T., Baker, N., Vignelles, D., Stenchikov, G., Shevchenko, I., Smith, J., Bedka, K., Kesarkar, A., Singh, V., Bhate, J., Ravikiran, V., Durga Rao, M., Ravindrababu, S., Patel, A., Vernier, H., Wienhold, F. G., Liu, H., Knepp, T. N., Thomason, L., Crawford, J., Ziemba, L., Moore, J., Crumeyrolle, S., Williamson, M., Berthet, G., Jégou, F., and Renard, J.-B., BATAL: The Balloon Measurement Campaigns of the Asian Tropopause Aerosol Layer, Bulletin of the American Meteorological Society, 99 (5), 955-973, doi:10.1175/BAMS-D-17-0014.1, 2018.

Warren, J. L., and Zolensky, M. E., Collection and curation of interplanetary dust particles recovered from the stratosphere by NASA, In: Analysis of Interplanetary Dust, American 
1714 Institute of Physics, M. Zolensk, T., Wilson, F. Rietmeijer, G. Flynn eds., New York, 245-253, 17151994.

1716

1717

1718

1719

1720

1721

1722

1723

1724

1725

1726

1727

1728

1729

1730

1731

1732
Weigel, R., Volk, C. M., Kandler, K., Hösen, E., Günther, G., Vogel, B., Grooß, J.-U., Khaykin, S., Belyaev, G. V., and Borrmann, S., Enhancements of the refractory submicron aerosol fraction in the Arctic polar vortex: feature or exception?, Atmos. Chem. Phys., 14, 12319-12342, 2014.

Yu P., Toon O. B., Neely R. R., Martinsson B. G., and Brenninkmeijer C. A., Composition and physical properties of the Asian tropopause aerosol layer and the North American tropospheric aerosol layer, Geophys. Res. Lett., 42, 2540-2546, 2015.

Zuev, V.V., Zueva, N.E., Koutsenogii, P.K. and Savelyeva, E.S., Volcanogenic nanosized carbon aerosol in the stratosphere, Chemistry for sustainable development, 22, 81-86, 2014.

Zuev, V.V., Zueva, N.E. and Savelyeva, E.S., Temperature and ozone anomalies as indicators of volcanic soot in the stratosphere, Atmospheric and oceanic optics, 28(1), 100-106, doi: 10.1134/S1024856015010169, 2015. 